\title{
Molecular mechanisms of cancer cachexia-induced muscle atrophy (Review)
}

\author{
WEI YANG $^{1^{*}}$, JIANHUI HUANG ${ }^{2 *}$, HUI WU ${ }^{3}$, YUQING WANG $^{3}$, ZHIYIN DU $^{3}$, \\ YUANBO LING $^{3}$, WEIZHUO WANG ${ }^{3}$, QIAN WU ${ }^{1}$ and WENBIN GAO ${ }^{1}$ \\ ${ }^{1}$ Department of Oncology, The Third Affiliated Hospital of Shenzhen University, Shenzhen, \\ Guangdong 518000; ${ }^{2}$ Department of Oncology, Lishui Municipal Central Hospital, Lishui, Zhejiang 323000; \\ ${ }^{3}$ Department of Clinical Medicine, Anhui University of Science and Technology, Huainan, Anhui 232001, P.R. China
}

Received May 16, 2020; Accepted September 9, 2020

DOI: $10.3892 / \mathrm{mmr} .2020 .11608$

\begin{abstract}
Muscle atrophy is a severe clinical problem involving the loss of muscle mass and strength that frequently accompanies the development of numerous types of cancer, including pancreatic, lung and gastric cancers. Cancer cachexia is a multifactorial syndrome characterized by a continuous decline in skeletal muscle mass that cannot be reversed by conventional nutritional therapy. The pathophysiological characteristic of cancer cachexia is a negative protein and energy balance caused by a combination of factors, including reduced food intake and metabolic abnormalities. Numerous necessary cellular processes are disrupted by the presence of abnormal metabolites, which mediate several intracellular signaling pathways and result in the net loss of cytoplasm and organelles in atrophic skeletal muscle during various states of cancer
\end{abstract}

Correspondence to: Mr. Wenbin Gao, Department of Oncology, The Third Affiliated Hospital of Shenzhen University, 47 Youyi Road, Shenzhen, Guangdong 518000, P.R. China

E-mail: drwenbingao@163.com

*Contributed equally

Abbreviations: LC, lung cancer; Ang II, angiotensin II; IGF-1, insulin-like growth factor 1; ER, endoplasmic reticulum; UPS, ubiquitin-proteasome system; Ub, ubiquitin; MAFbx, muscle atrophy Fbox-1 protein; MuRF1, muscle ring finger protein 1; AMPK, AMP-activated protein kinase; LLC, Lewis lung carcinoma; MyHC, myosin heavy chain; p70S6K, 70-kDa ribosomal protein S6 kinase; $4 \mathrm{EBP}, 4 \mathrm{E}$ binding protein 1 ; IKK, I $\kappa \mathrm{B}$ kinase; NIK, NF- $\kappa \mathrm{B}$-inducing kinase; ALP, autophagy-lysosomal proteolytic; miRNAs/miRs, microRNAs; PIF, proteolysis-inducing factor; UPR, unfolded protein response; PERK, protein kinase-like ER eukaryotic translation initiation factor $2 \alpha$ kinase; IRE1, inositol-requiring protein; ATF6, activating transcription factor 6; VL, vastus lateralis; Mfn2, mitofusin-2; PDK4, pyruvate dehydrogenase kinase 4; ZQ-SJZ, Sijunzi decoctions (Zhen-Qi); ERBA, epoxy-resibufogenin-3-acetate; PDTC, pyrrolidine dithiocarbamate

Key words: cancer cachexia, muscle atrophy, mechanism, signaling pathway, transcription factor, therapy cachexia. Currently, the clinical morbidity and mortality rates of patients with cancer cachexia are high. Once a patient enters the cachexia phase, the consequences are difficult to reverse and the treatment methods for cancer cachexia are very limited. The present review aimed to summarize the recent discoveries regarding the pathogenesis of cancer cachexia-induced muscle atrophy and provided novel ideas for the comprehensive treatment to improve the prognosis of affected patients.

\section{Contents}

1. Introduction

2. Activation of the UPS

3. Induction of proinflammatory factors

4. Regulation of signaling pathways, transcription factors and microRNAs (miRNAs/miRs)

5. Cell autophagy/lysosomal and $\mathrm{Ca}^{2+}$-dependent protein degradation pathways

6. Endoplasmic reticulum stress and mitochondrial dysfunction

7. Other receptors and substances that affect metabolism

8. Treatment of muscle atrophy caused by cancer cachexia

9. Conclusion

\section{Introduction}

Cancer cachexia is a multifactorial syndrome characterized by a continuous decline in skeletal muscle mass, with or without a reduction in adipose tissue, which cannot be reversed by conventional nutritional treatments and eventually leads to progressive muscle dysfunction (1). The diagnostic criteria are a weight loss of $>5 \%$, or a weight loss $>5 \%$, or a weight loss $>2 \%$ in individuals with a body mass index $<20 \mathrm{~kg} / \mathrm{m}^{2}$ or sarcopenia (2). Alternative criteria are a skeletal muscle index of the extremities meetings the criteria for sarcopenia (males, $<7.26 \mathrm{~kg} / \mathrm{m}^{2}$; females, $<5.45 \mathrm{~kg} / \mathrm{m}^{2}$ ) and a weight loss of $>2 \%$ (3).

The pathophysiological characteristic of cancer cachexia is a negative protein and energy balance caused by a combination of factors, such as reduced food intake and metabolic abnormalities (4-7). Cachexia develops during the progression of a number of types of malignant tumor, especially upper 
gastrointestinal cancer and lung cancer (LC). According to statistical analyses, $>80 \%$ of patients with advanced pancreatic and gastric cancer and $\sim 60 \%$ of patients with advanced LC may have cancer cachexia (8). A previous survey also revealed that the prevalence of geriatric cancer cachexia at a geriatric oncology clinic was $65 \%$ (9). The clinical symptoms of cancer cachexia in patients include muscle atrophy and weight loss, accompanied by various other manifestations, such as loss of appetite, anorexia, fatigue, anemia, edema and hypoproteinemia, which significantly impact the quality of life of the patients (10). In addition, cancer cachexia has been discovered to reduce the patient sensitivity and tolerance to treatment and shortens their survival (11).

To the best of our knowledge, the mechanism by which cancer cachexia causes muscle atrophy is not completely clear. Skeletal muscle protein undergoes decreased synthesis and increased degradation during cancer cachexia (1); these changes are attributed to the upregulation of inflammatory mediators (12-14), the activation of related transcription factors (15) and signaling pathways (16-18), abnormalities in the expression of angiotensin II (Ang II) (19), insulin-like growth factor-1 (IGF-1) (20) and various receptors $(21,22)$, proteins and kinases (23), and organelle dysfunction (24). These processes eventually lead to muscle atrophy during the development of cancer cachexia. To date, three main pathways of skeletal muscle protein degradation have been identified: The ubiquitin (Ub)-proteasome, cell autophagy/lysosomal and $\mathrm{Ca}^{2+}$-activated degradation pathways (25-27). The most significant of these pathways is the Ub-proteasome system (UPS) (28). The activation of the above pathways is often accompanied by the presence of inflammatory mediators, including IL-1 $\beta$ (14), IL-6 (29) and TNF $\alpha$ (30), and the phosphorylation (17) or abnormal expression of important molecules (18). The abnormal catabolism is often related to the dysfunction of organelles, such as the endoplasmic reticulum (ER) (31) and mitochondria (32). Proteins such as Ang II (19) and IGF-1 (20) are also involved in cancer cachexia-induced muscle atrophy.

The pathogenesis of cancer cachexia-induced muscle atrophy is complex and has not been fully elucidated. Currently, no particular effective treatment method is available; The most effective treatment includes a multitarget approach including appetite stimulants, inhibitors of cachectic signaling molecules, along with nutritional supplementation and physical activity (33). The present review aimed to summarize the pathogenesis and comprehensive treatment of muscle atrophy caused by cancer cachexia and provide novel ideas for the early detection and timely intervention of cancer cachexia-induced muscle atrophy.

\section{Activation of the UPS}

Protein degradation in cells is a carefully controlled process, and the UPS serves an important role in the process of skeletal muscle protein degradation (28). The UPS is composed of $\mathrm{Ub}$ and a series of related enzymes, including Ub-activating enzyme (E1), Ub-conjugating enzyme (E2), Ub-ligating enzyme (E3) and proteasomes (34). In this system, proteins are targeted for degradation by covalent ligation to $\mathrm{Ub}$, a 76 amino acid residue protein (35). Ub must first be activated by E1 (36) and then transferred to E2 (37). E2 recognizes
E3, which then specifically recognizes and binds to specific proteins to form a Ub-protein chain $(38,39)$. A proteasome is a large, $26 \mathrm{~S}$, multi-catalytic protease that degrades polyubiquitinated proteins to small peptides $(40,41)$. Currently, two E3 protein ligases have been proven to be very active in the proteolysis of muscle atrophy, namely, muscle atrophy Fbox-1 protein (MAFbx; also called atrogin-1) and muscle ring finger protein 1 (MuRF1) (42), which are regulated by a variety of signaling pathways, such as the NF- $\kappa \mathrm{B}$, IL-6 and p38 MAPK signaling pathways $(12,43-46)$.

A number of proinflammatory and transfer factors, in addition to the activation of several pathways have been identified in skeletal muscle and were illustrated to be involved in cancer cachexia-induced muscle atrophy; for example, TNF- $\alpha$ (47), Twist1 (48), the NF- $\kappa B$ signaling pathway (49) and the p38 MAPK signaling pathway (45), which were all discovered to be upregulated. The overexpression of proinflammatory factors, transfer factors or members of signaling pathways in skeletal muscle in the context of cancer cachexia eventually converge on the MuRF1 and MAFbx of the UPS, promoting proteasome hydrolysis in the UPS and leading to skeletal muscle protein degradation (50-53).

In vivo and in vitro studies have reported that upregulation of stromal cell-derived factor 1 (SDF1) or its receptor C-X-C chemokine receptor type 4 (CXCR4) partially protected against muscle atrophy (54-56). Furthermore, a clinical study identified that SDF1 and CXCR4 expression levels in the rectus abdominis of patients with cancer were inversely associated with MAFbx and MuRF1 expression levels in muscle atrophy (57). A previous study also illustrated that the administration of recombinant adeno-associated viral vectors promoted the overexpression of the SMAD7 gene in skeletal and cardiac muscle, reduced SMAD2/3 phosphorylation downstream of activin receptor type-2B (ActRIIB) and inhibited the expression levels of the muscle atrophy-associated Ub ligases MuRF1 and MAFbx to prevent muscle atrophy (58). Contrary to these findings, in another previous study, the expression levels of the E3 ligases MuRF1 and MAFbx were analyzed using reverse transcription-quantitative PCR (RT-qPCR), and no relationship was identified between the mRNA expression levels and weight loss in cancer (59).

Nonetheless, the majority of the evidence for the involvement of the UPS in cancer cachexia conditions is currently derived from animal models of muscle wasting. Further investigations involving more samples are required to investigate the regulatory patterns of the UPS in human muscle wasting, secondary to the above pathologies in cancer cachexia.

\section{Induction of proinflammatory factors}

IL-6. Numerous proinflammatory factors have been discovered to serve important roles in the muscle atrophy caused by cancer cachexia $(13,29,60,61)$. IL-6 is produced by macrophages (62) and fibroblasts (63) and was also found to be secreted by tumor cells (64). Several studies have reported that severe weight loss due to cancer cachexia was associated with increased circulating IL-6 levels (65-67). Clinical studies have also revealed that compared with healthy controls, patients with non-small cell LC (NSCLC) with cachexia had smaller muscle fiber cross-sectional areas and significantly increased 
plasma IL-6 levels (68). The IL-6/Janus kinase (JAK)/STAT3 signaling pathway was discovered to have an essential role in the progression of cancer cachexia by regulating the inflammatory response $(13,60)$. Pin et al $(61)$ intraperitoneally injected ES-2 human ovarian cancer cells into Nod-SCID $\gamma$ mice to establish a cancer cachexia model; the experimental studies revealed significantly upregulated IL-6 and phosphorylated STAT3 levels in the plasma and ascites of model mice compared with control mice. Similarly, ES-2-conditioned medium directly induced high levels of STAT3 phosphorylation in $\mathrm{C} 2 \mathrm{C} 12$ myotubes and caused muscle atrophy in the mice. Further evidence also suggested that an IL-6/STAT3 signaling inhibitor (INCB018424) restored myotube size (61). Another previous study also reported a dose-dependent inhibitory effect of IL- 6 on mTOR activity in a cancer cachexia model and discovered that the suppression of mTOR activity by IL- 6 was dependent on AMP-activated protein kinase (AMPK) activation and independent of STAT signaling in myotubes (29). In addition to relieving the suppression of anabolic signaling, AMPK inhibition also reduced IL-6-induced MAFbx and ubiquitinated protein expression. Therefore, on the one hand, IL- 6 has been found to inhibit the activity of mTOR through AMPK activation, thereby inhibiting the synthesis of muscle protein, while on the other hand, the activation of AMPK promoted the hydrolysis of muscle protein by the UPS (Fig. 1) (29).

$T N F-\alpha$. TNF- $\alpha$ is an inflammatory factor secreted by macrophages and produced by tumor cells, and it has been confirmed to be a crucial factor associated with cancer cachexia-induced muscle wasting (69-71). In particular, TNF- $\alpha$ was reported to have a direct catabolic effect on skeletal muscle, which caused muscle wasting through the induction of $\mathrm{Ub}$ gene expression of the UPS (Fig. 1) (30,72). Research has also discovered that TNF- $\alpha$ exposure upregulated MAFbx mRNA expression levels within $2 \mathrm{~h}$ in $\mathrm{C} 2 \mathrm{C} 12$ myotubes, and that exposing myotubes to TNF- $\alpha$ also promoted the general activation of p38 MAPK. MAFbx upregulation and the associated increase in Ub-conjugating activity were both inhibited by p38 inhibitors, either SB203580 or curcumin. These data indicated that TNF- $\alpha$ may act via p38 MAPK to increase MAFbx gene expression levels in skeletal muscle to induce muscle atrophy (Fig. 1) (12).

Matsuyama et al (73) established two sets of cancer cachexia model mice and evaluated the levels of 23 circulating cytokines and TGF- $\beta$ family members; IL- 6 , TNF- $\alpha$ and activin A levels were elevated in the two groups of cachexia model mice. In addition, MAFbx and MuRF1 mRNA expression levels in the gastrocnemius muscle were significantly upregulated in both groups of tumor-bearing mice, leading to skeletal muscle wasting. However, further evidence is required to prove that TNF- $\alpha$ can affect MAFbx and MuRF1 mRNA expression levels.

In vitro studies have further revealed that tumor-derived TNF- $\alpha$ and activating factors in the exosomes of osteosarcoma cells (the murine K7M2 osteosarcoma cell line) activated Notch signaling in muscle-derived stem cells, which subsequently induced skeletal muscle atrophy (74). In addition, the TNF- $\alpha$ signal was transduced in part through the activation of $\mathrm{NF}-\kappa \mathrm{B}$, a process that involves Ub conjugation and the proteasomal

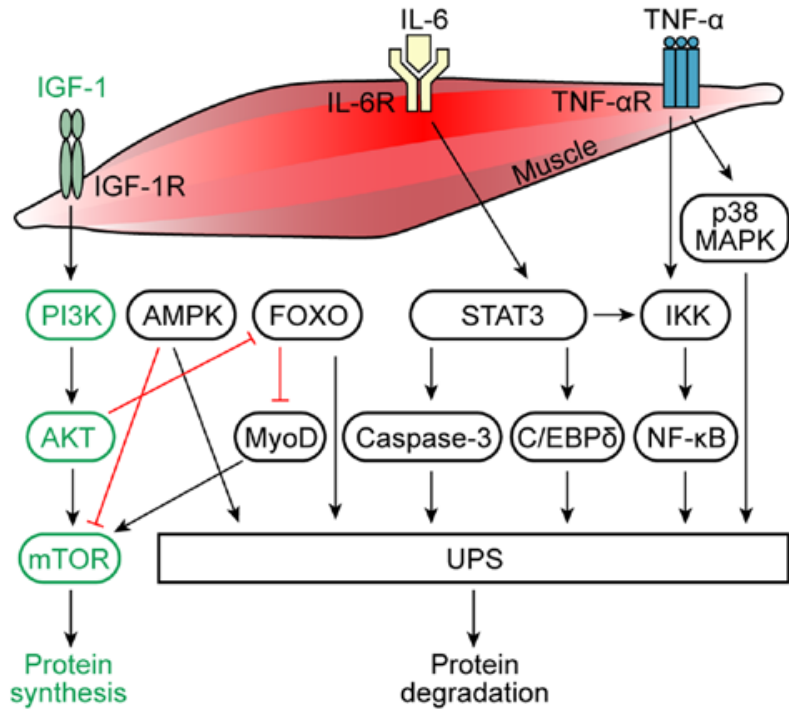

Figure 1. Molecules and signaling pathways involved in muscle protein synthesis and degradation. Under physiological conditions, IGF-1 activates AKT through a PI3K-dependent process, leading to the activation of mTOR and thus resulting in the increased proliferation of muscle cells and increased protein synthesis in muscle cells. IL- 6 and TNF- $\alpha$ are considered to be the main mediators of the inflammation in muscle atrophy caused by cancer cachexia. The binding of IL- 6 to its receptor induces AMPK and STAT3 expression. STAT3 induces the activation of the IKK/NF- $\mathrm{B}$ pathway and caspase-3 and C/EBPS expression, which activates the UPS, causing muscle protein degradation. AMPK is a downstream target of IL-6 signaling, which inhibits the mTOR cascade, and activates the UPS. Physiologically, AKT inhibits FOXO, which promotes protein synthesis. In cancer cachexia, FOXO inhibits MyoD and activates the UPS, thereby promoting protein degradation. Moreover, the activation of $N F-\kappa B$ due to the degradation of the I $\kappa B$ inhibitor by IKK is TNF- $\alpha$-dependent. The $N F-\kappa B$ pathway can further activate the UPS to cause muscle protein degradation. TNF- $\alpha$ can also induce the p38 MAPK pathway, which activates the UPS. IGF-1, insulin-like growth factor 1; AMPK, AMP-activated protein kinase; IKK, IкB kinase; $\mathrm{C} / \mathrm{EBP} \delta$, CCAAT/enhancer-binding protein $\delta$; UPS, ubiquitin-proteasome system; MyoD, myoblast determination protein 1; R, receptor.

degradation of I $\kappa \mathrm{B}$ (Fig. 1) (30). The importance of TNF- $\alpha$ in regulating cancer cachexia-induced skeletal muscle atrophy requires further verification in clinical settings; however, the current data indicates that TNF- $\alpha$ may be an important inducer that can directly or indirectly mediate the UPS and thus lead to skeletal muscle atrophy.

$I L-1$. IL-1 is a cytokine that is produced by monocytes, endothelial cells, fibroblasts and other cell types in response to infection and exists in two forms: IL-1 $\alpha$ and IL-1 $\beta$. IL-1 was identified to be an important factor in cachexia $(14,75,76)$. For example, Cannon et al (75) established squamous cell carcinoma cachexia model mice and detected and quantified the levels of 18 cytokines and chemokines, including IL-1 $\beta$, IL-1 $\alpha$, IL-6, TNF- $\alpha$ and IFN- $\gamma$, among others. The results revealed that only IL-1 $\beta$ levels were significantly elevated in the tumor-bearing mice compared with the controls. In addition, MuRF1 levels were significantly upregulated in the carcinoma cachexia model mice compared with the controls. Therefore, these findings indicated that IL- $1 \beta$ may mediate MuRF1 regulation and lead to muscle wasting, and therefore atrophy in tumor-bearing mice. In another study, mice implanted with Lewis LC (LLC) cells revealed a robust increase in the expression of IL-1 $\beta$ in the hypothalamus. Concurrent with 
the presence of central inflammation, the atrophy program was activated in the skeletal muscle as indicated by the upregulation of MAFbx, MuRF1 and FOXO1 expression levels, which occurred in the context of muscle wasting in the tumor-bearing animals. The study further demonstrated that central nervous system (CNS) IL-1 $\beta$ signaling alone evoked a catabolic program in the muscle, rapidly inducing atrophy. This effect was dependent on hypothalamic-pituitary-adrenal axis activation, as CNS IL-1 $\beta$-induced atrophy was discovered to be abrogated by adrenalectomy (14).

To understand the role of IL- $1 \alpha$ in breast cancer cachexia progression in vivo, a previous study investigated the growth of MCF-7 breast cancer cells overexpressing a secreted form of IL-1 $\alpha$ (MCF-7IL-1 $\alpha$ ) in nude mice; animals implanted with MCF-7IL-1 $\alpha$ cells were cachectic, which associated with increased serum leptin levels, but not with other known cachexia-inducing cytokines, including IL-6, TNF or IFN- $\gamma$ (77). The results suggested that IL-1 $\alpha$ may induce cachexia by affecting leptin-dependent metabolic pathways.

As a master cytokine involved in the pathophysiological characteristics of cancer cachexia, preclinical studies have demonstrated the role of IL-1 in mediating muscle wasting in cachexia $(14,77)$, which may reveal new therapeutic targets for muscle wasting diseases.

\section{Regulation of signaling pathways, transcription factors and microRNAs (miRNAs/miRs)}

Inhibition of the PI3K/AKT/mTOR signaling pathway. Under physiological conditions, growth factors and nutrients activate AKT through PI3K-dependent processes that activate mTOR, leading to increased muscle cell proliferation and muscle protein synthesis (Fig. 1) (78-80). The serine-threonine kinase AKT, as a downstream target of PI3K, was discovered to serve an important role in myogenic differentiation (81). The expression of constitutively active forms of AKT was discovered to markedly enhance myotube formation and the expression levels of the muscle-specific proteins myoblast determination protein 1 (MyoD), creatine kinase, myosin heavy chain (MyHC) and desmin (81). The activation of the PI3K/AKT signaling pathway stimulates mTOR signaling cascades, modulating two master molecules associated with the initiation of mRNA translation, namely, 70-kDa ribosomal protein S6 kinase (p70S6K) $(82,83)$ and eukaryotic initiation factor 4E binding protein 1 (4EBP1) $(84,85)$.

The PI3K/AKT signaling pathway was illustrated to prevent the induction of the muscle-specific Ub ligases MAFbx and MuRF1 through a mechanism involving the AKT-mediated inhibition of the FOXO family of transcription factors (Fig. 1) (86,87). In addition, a previous study used western blotting to analyze skeletal muscle and liver tissue extracts from 8 patients with pancreatic cancer with cachexia and 8 patients with nonmalignant tumors; compared with the patients without cachexia, the patients with cachexia had significantly reduced levels of $\mathrm{MyHC}$ and actin in the muscle, a 55\% decrease in AKT protein expression levels, a 4-fold decrease in the abundance and/or phosphorylation of the transcription factors FOXO1 and FOXO3a, and significant reductions in the expression levels of mTOR $(-82 \%)$ and p70S6K (-39\%) (16). This study demonstrated that the cachexia-associated loss of AKT-dependent signaling in human skeletal muscle was associated with the decreased activity of regulators of protein synthesis (16).

Cachexia was discovered to decrease mTOR phosphorylation, and the phosphorylation of mTOR substrates, S6 ribosomal protein and 4EBP, independent of AKT activation. These changes in mTOR-related protein signaling pathways were accompanied by modest increases in the levels of Beclin-1, which is associated with autophagy, but not the protein ubiquitination or cardiomyocyte apoptosis in an ApcMin/+ mouse model of colorectal cancer. The study suggested that the loss of cardiac mass during cachexia progression in the ApcMin/+ mice was associated with the AKT-independent suppression of anabolic signaling and increased autophagy (88). Furthermore, the mTOR signaling pathway was demonstrated to control myofiber formation and myofiber growth during muscle regeneration via kinase-independent and kinase-dependent mechanisms, respectively (89). A previous study discovered that IGF-2 expression during the early phase of regeneration was sensitive to rapamycin in an mTOR kinase-independent manner, whereas p70S6K was required for mTOR kinase-dependent myofiber growth (89). In summary, the findings of these previous reports indicated that the PI3K/AKT/mTOR signaling pathway may serve an important role in the process of muscle protein synthesis, and that the regulation of this pathway is very complicated, which has undoubtedly influenced the direction of future $\mathrm{PI} 3 \mathrm{~K} / \mathrm{AKT} / \mathrm{mTOR}$ pathway research.

STAT3 signaling pathway. Cachexia phenotypes, such as skeletal muscle wasting, have been causally linked to the cytokine-activated transcription factor STAT3. Binding of IL-6 to its receptor induces STAT3, which was found to lead to proteolysis and muscle wasting $(13,90,91)$. STAT3 may be considered as a therapeutic target for patients with cachexia with gastric, lung and breast cancer. For example, a previous study identified that IL-6 mediated STAT3 activation in cachectic patients with gastric and breast cancer (60). STAT3 can also induce the $\mathrm{I} \kappa \mathrm{B}$ kinase $(\mathrm{IKK}) / \mathrm{NF}-\kappa \mathrm{B}$ signaling pathway, which was discovered to mediate apoptosis and muscle atrophy (92). A previous study with $\mathrm{C} 2 \mathrm{C} 12$ myotubes cultured in a simulated cachexia environment revealed that IFN- $\gamma$ and TNF- $\alpha$ promoted STAT3 phosphorylation on the myofiber-specific cytoplasmic Y705 residue by activating JAK kinase (92). Interestingly, pY505-STAT3 and NF- $\mathrm{B}$ formed a complex that rapidly entered the nucleus and bound the inducible nitric oxide synthase (iNOS) promoter to activate the iNOS/nitric oxide (NO) pathway, which induced muscle atrophy (92). Moreover, another study identified that cancer cachexia activated STAT3 in the muscle to stimulate muscle atrophy via two signaling pathways; in one pathway, phosphorylated (p)-STAT3 stimulated caspase-3 transcription and activity, which induced the activation of the UPS; while in the second pathway, p-STAT3 stimulated CCAAT/enhancer-binding protein $\delta$ expression and activity, which increased myostatin and MAFbx and MuRF1 (Fig. 1) (17).

$N F-\kappa B$ signaling pathway. $\mathrm{NF}-\kappa \mathrm{B}$ resides in the cytosol of cells and is tightly bound via covalent bonds to $I \kappa B$, which maintains it in an inactive state (93). NF- $\kappa \mathrm{B}$ activation occurs 
by severing the covalent bonds with I $\mathrm{B}$ via the action of IKK. IKK is a kinase that phosphorylates $I \kappa B$ and initiates $I \kappa B$ degradation via the Ub proteasome pathway, leaving $\mathrm{NF}-\kappa \mathrm{B}$ free and active (94). The canonical activation of NF- $\kappa \mathrm{B}$ due to the degradation of the inhibitor of IKB $\alpha / \beta$ by IKK is dependent on TNF (93). The activation of NF- $\kappa B$ was identified as a key event in the processes that mediate muscle atrophy (95). $\mathrm{NF}-\kappa \mathrm{B}$-inducing kinase (NIK) serves as a proximal inducer of the IKK complex, which is an upstream convergence point for numerous signals leading to $\mathrm{NF}-\kappa \mathrm{B}$ activation. The overexpression of NIK in primary human skeletal muscle myotubes increased skeletal muscle atrophy biomarkers, while NIK knockdown significantly attenuated glucocorticoid-induced increases in NIK and MAFbx (49). Multiple studies have revealed that the $\mathrm{NF}-\kappa \mathrm{B}$ signaling pathway also mediated muscle atrophy by activating the downstream iNOS/NO pathway $(92,96)$. In addition, another study investigated the effect of muscle metabolism on patients with cachexia and advanced NSCLC; compared with healthy volunteers, patients with NSCLC had significantly upregulated NF- $\kappa \mathrm{B}$ mRNA expression levels (18).

p38 MAPK signaling pathway. MAPK family proteins, which are evolutionarily conserved serine/threonine protein kinases, serve a central role in the p38 signal transduction pathway. ERKs, p38 MAPK, JNKs and ERK5 represent the four MAPK subfamilies (97). The p38 MAPK signaling pathway was found to serve a critical role in the regulation of E3 ligase expression and skeletal muscle atrophy (98-100) and is activated by a number of extra- and intracellular stimuli, including the proinflammatory factors TNF- $\alpha(12,101)$, endotoxin (102) and reactive oxygen species (ROS), as well as stressors such as oxidative stress (45).

A previous study identified that oxidative stress-induced the expression of an autophagy-related gene, autophagy related 7 (ATG7), in the autophagy-lysosomal proteolytic (ALP) pathway, and the E3 ligases (MuRF1 and MAFbx) in the UPS were temporally associated with the activation of the $\mathrm{p} 38$ MAPK pathway independent of NF- $\mathrm{B}$ - and FOXO-dependent transcriptional activation in cultured muscle cells. These findings provided direct evidence for the functional role of the p38 MAPK signaling pathway in mediating oxidative stress through the ALP pathway in cachectic muscle wasting (45). Based on the above findings, a model was proposed in which oxidative stress-induced p38 MAPK activation was suggested to initiate and participate in cachectic muscle wasting through both the UPS and ALP mechanisms.

Transcription factors. Several transcription factors have been identified to play important roles in muscle atrophy, particularly FOXO factors $(86,87,103)$, thus the inhibition of FOXO factors is an attractive approach to combat muscle wasting. One study showed that when FOXO1 expression was blocked both in cells and in mice, the expression levels of MyoD, a myogenic factor, were upregulated (Fig. 1) (104). Moreover, constitutively active FOXO3 acted on the MAFbx promoter to cause MAFbx transcription and enhance the atrophy of myotubes and muscle fibers (87). In animal models of cancer cachexia, bioinformatics analysis of upregulated gene transcripts that required FOXO revealed an enrichment of the proteasome, activator protein 1, and IL-6 pathways, and included several atrophy-related transcription factors, such as STAT3, Fos and CCAAT/enhancer-binding protein $\beta(\mathrm{C} / \mathrm{EBP} \beta)$. Furthermore, the study validated these findings in limb muscles and the diaphragm through RT-qPCR and demonstrated that FOXO1 and FOXO3a were sufficient to increase STAT3, Fos, C/EBP $\beta$ and the $\mathrm{C} / \mathrm{EBP} \beta$ target gene, E3-Ub-protein ligase Ubr2 (15). Experimental studies have also explored the function of the transcription factor Twist1 in cancer-driven muscle atrophy; for example, a previous study demonstrated that Twist1 expression drove the upregulation of MuRF1 and MAFbx expression levels, leading to muscle protein degradation (48).

A previous study analyzed the transcriptomes of cells in atrophied skeletal muscle of cancer cachexia model mice and revealed that the involved transcription factors and transcription factor families included Oct1, sex-determining region $\mathrm{Y}$ protein, myogenin, TNF receptor superfamily member 25 , zinc finger protein ZIC 2, T-Box transcription factor 5, sterol regulatory element-binding protein 1, STAT, PU1, T3R, TAL1BETAITF2, heat shock factor protein, lymphoid enhancer-binding factor 1, S8, protein C-ets-1 and SOX9_BP1. In addition, various transcription factors with specific effects on myogenesis were identified, including myogenin, FOXO3, NF- $\kappa$ B p65 and paired box 1 (105). Furthermore, Marchildon et al (106) found that myoblasts exposed to an in vitro cancer cachexia environment exhibited upregulated $\mathrm{C} / \mathrm{EBP} \beta$ expression, which led to diminished myogenin expression and myogenesis.

miRNAs. To further understand the pathogenesis of cancer cachexia, previous studies have conducted experiments comprehensively analyzing the muscle atrophy network regulated by miRNAs. Indeed, researchers have predicted new miRNA/mRNA interactions, such as miR-27a/FOXO1, miR-27a/myocyte-specific enhancer factor 2C (MEF2C), miR-27b/stromal cell-derived factor 1 (CXCL12), miR-27b/MEF2C, miR-140/CXCL12, miR-199a/caveolin-1 and miR-199a/JunB, which may cause muscle atrophy in cancer cachexia (107). In addition, a previous study evaluated the miRNA profile of cancer cachexia-induced skeletal muscle atrophy in a mouse model and identified 9 significantly differentially expressed miRNAs associated with cancer, intercellular signaling and cell development (108). Overall, these results provided a basis for future research into genetic targets for reducing muscle loss in cancer cachexia (108).

\section{Cell autophagy/lysosomal and $\mathrm{Ca}^{2+}$-dependent protein degradation pathways}

The cell autophagy/lysosomal and $\mathrm{Ca}^{2+}$-dependent protein degradation pathways are two other pathways currently considered to be involved in skeletal muscle protein degradation.

Cell autophagy/lysosomal protein degradation. Previous studies have noted the important role of the autophagy-lysosome system in regulating muscle mass, in which several key components of the autophagy machinery were discovered to be transcriptionally upregulated during muscle wasting (109-111). A colon-26 (C26) cancer cachexia mouse model was established to observe the effects of autophagy inhibition (Beclin-1 
knockout) or promotion [tumor protein p53 inducible nuclear protein 2 (TP53INP2/DOR) overexpression] on cancer-induced muscle loss; the results revealed that Beclin-1 knockout could not prevent muscle atrophy in tumor-bearing mice and that TP53INP2-mediated autophagy exacerbated the muscle loss. Furthermore, an increase in autophagy was shown to clearly lead to a decrease in muscle mitochondrial function in another study (112). A recent report identified that activin A served in an autocrine manner to promote the synthesis and secretion of IL-6 from cancer cells. The inhibition of activin signaling reduced the production of IL-6 in cancer cells and the ability of cancer cells to accelerate autophagy in non-cancerous cells in vivo, which reversed cachexia and counteracted the loss of all measured muscle groups (Fig. 2) (113). In addition, oxidative stress-induced expression of the autophagy-related gene ATG7 in the ALP pathway was found to be temporally associated with activation of the p38 MAPK signaling pathway (Fig. 2) (45).

$\mathrm{Ca}^{2+}$-dependent protein degradation. Currently, to the best of our knowledge, little is known about the relevance of the $\mathrm{Ca}^{2+}$-dependent proteolytic system in cancer cachexia. Previous research has demonstrated that proteolysis-inducing factor (PIF) induced muscle loss in cancer cachexia through its high-affinity membrane bound receptor (114). In vitro, the binding of PIF to its receptor in skeletal muscle triggered an increase in $\mathrm{Ca}^{2+}$, which initiated the $\mathrm{Ca}^{2+}$-dependent proteolytic system, leading to an increase in protein degradation (Fig. 2) (114). Pin et al (22) established experimental models of cachexia using Yoshida AH-130 liver cancer cells and $\mathrm{C} 26$ colon cancer cells; the results revealed that calpain-1 was overexpressed in cachexia model rats with AH-130 liver cancer, while the expression levels of calpastatin (a physiological $\mathrm{Ca}^{2+}$-dependent protease inhibitor) expression were downregulated. Interestingly, these data indicated, for the first time, that the $\mathrm{Ca}^{2+}$-dependent proteolysis system was also overactivated in the $\mathrm{C} 26$ rat model. However, interference with $\mathrm{Ca}^{2+-}$ dependent proteolysis did not alter the course of muscle wasting in experimental cancer cachexia.

\section{ER stress and mitochondrial dysfunction}

ER stress. Skeletal muscle contains a plentiful network of ER, which serves an important role in the regulation of proteostasis and $\mathrm{Ca}^{2+}$ homeostasis. Protein folding in the ER is exquisitely sensitive to changes in the environment, which leads to disrupted protein folding to cause the accumulation of unfolded or misfolded proteins, a condition termed ER stress $(115,116)$. The ER manages such stress by initiating the unfolded protein response (UPR), which is controlled by three transmembrane proteins, namely, RNA-dependent protein kinase-like ER eukaryotic translation initiation factor $2 \alpha$ kinase (PERK) (117), inositol-requiring protein 1 (IRE1) $(117,118)$ and activating transcription factor 6 (ATF6) $(119,120)$, which are activated to alleviate ER stress. In the absence of stress, the intra-luminal domains of PERK, IRE1 and ATF6 bind to the ER luminal protein glucose-regulated protein 78 (GRP78), also known as heat shock protein $\mathrm{A}$ or binding immunoglobulin protein. However, the accumulation of misfolded and/or unfolded proteins in the ER lumen leads to the dissociation of PERK,

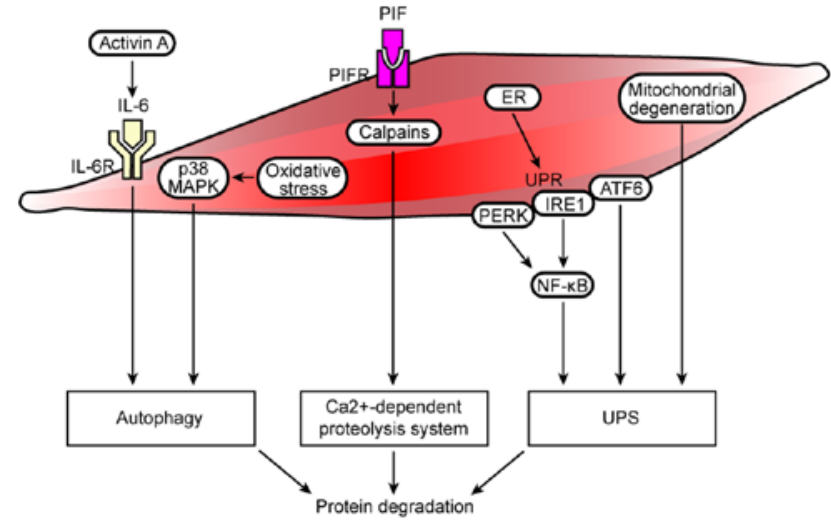

Figure 2. Cell autophagy/lysosomal and $\mathrm{Ca}^{2+}$-dependent protein degradation pathways, ER stress and mitochondrial dysfunction are involved in muscle protein degradation in cancer cachexia. In cancer cachexia, increased activin A expression activates the IL- 6 signaling pathway, and oxidative stress induces activation of the p38 MAPK signaling pathway, resulting in autophagy and protein degradation. The overexpression of $\mathrm{Ca}^{2+}$-dependent proteases (calpains) activates the $\mathrm{Ca}^{2+}$-dependent proteolysis system, resulting in increased protein degradation. In addition, the ER manages such stress by initiating the UPR, which is controlled by three transmembrane proteins, namely, PERK, IRE1 and ATF6. Optimal activation of NF- $\kappa \mathrm{B}$ during ER stress requires inputs from both IRE1 and PERK activities, and ATF6 may interact with protein degradation pathways, such as the UPS. Moreover, local mitochondrial degeneration in the muscle activates the UPS, which results in protein degradation. $\mathrm{R}$, receptor; PERK, protein kinase-like ER eukaryotic translation initiation factor $2 \alpha$ kinase; ER, endoplasmic reticulum; UPR, unfolded protein response; IRE1, inositol-requiring protein; ATF6, activating transcription factor 6; UPS, ubiquitin-proteasome system.

IRE1 and ATF6 from GRP78, thereby activating downstream signaling cascades (121). The main function of the UPR is to restore homeostasis (122), but excessive or prolonged activation of the UPR can lead to pathological conditions (116).

Previous studies have reported emerging roles of ER stress and the UPR in cancer cachexia-induced muscle atrophy $(31,123,124)$. In fact, markers of ER stress and the UPR were upregulated in the muscles of cachectic patients with cancer (124). Moreover, studies have shown that the optimal activation of NF- $\mathrm{KB}$ during ER stress requires inputs from both IRE1 and PERK activities in cancer cells (Fig. 2) (125). In addition, the mRNA and protein expression levels of ATF6 were significantly upregulated in the vastus lateralis (VL) of patients with LC-induced cachexia, and ATF6 was also discovered to potentially interact with protein degradation pathways, such as the UPS. The gene expression levels of MAFbx and MuRF1 were also significantly upregulated in the VL of LC-induced cachexia patients compared with healthy controls (124). Evidence from previous studies has also revealed that multiple markers of ER stress and the UPR, such as PERK, IRE1a and ATF6, were highly activated in the skeletal muscle of LLC and Apc(Min/+) mouse models of cancer cachexia. The inhibition of the UPR reduced the activity of the AKT/mTOR signaling pathway and upregulated the expression levels of MuRF1 and MAFbx and autophagy in LLC-bearing mice. Therefore, the study provided initial evidence to suggest that ER stress and the UPR pathway may be essential for maintaining skeletal muscle mass and strength, in addition to the protection against cancer cachexia (31).

Based on these aforementioned findings, some divergent views are notably present, and the majority of the studies 
regarding the regulation of ER stress and the UPR in cancer cachexia-induced muscle atrophy were performed using cultured cells or preclinical animal models. Therefore, additional studies in patients are required to obtain corroborative clinical data regarding ER stress, the UPR and cancer cachexia-induced muscle atrophy.

Mitochondrial dysfunction. Numerous studies have illustrated that muscle atrophy caused by cancer cachexia was related to mitochondrial dysfunction (126-130). For example, the expression of mitochondrial quality control (MQC) axis mediators was detected in rectus abdominis muscle biopsies from 18 elderly patients with gastric adenocarcinoma (9 with cancer cachexia and 9 without cachexia) and 9 controls; the expression levels of the mitotic protein Fis1 were upregulated in the patients with cancer cachexia, while the fusion index [mitofusin-2 (Mfn2)/Fis1 ratio] was decreased in the patients. Therefore, these results suggested that cachexia may be related to mitochondrial dynamics and signal transduction through the muscle MQC axis (24).

Previous studies have demonstrated that mitochondrial degeneration precedes muscle atrophy in the development of cancer cachexia in tumor-bearing mice, providing novel evidence for mitochondrial damage preceding cachexia-associated muscle loss (127). Neyroud et al (131) established a C26-induced cancer cachexia model in CD2F1 mice and observed the mitochondrial respiratory capacity and content of skeletal muscle. Indeed, skeletal muscle mitochondrial respiration, mitochondrial coupling and the mitochondrial content were all reduced.

An in vivo study using cancer cachexia model rats revealed that skeletal muscle loss was accompanied by morphologic alterations in fibers, such as mitochondrial disruption, dilatation of the sarcoplasmic reticulum and apoptotic nuclei. Moreover, upregulated expression levels of genes involved in proteolysis, such as MuRF1 and MAFBx, were observed in tumor-bearing animals. This study reported profound morphological changes in cancer cachectic muscle, which mainly included alterations in the sarcoplasmic reticulum and mitochondria (Fig. 2) (32).

\section{Other receptors and substances that affect metabolism}

Vitamin D receptor (VDR). The overexpression of the VDR in tumor-bearing animals has been reported to impair muscle regeneration and cause protein degradation. Therefore, caution should be exercised when considering vitamin D supplementation for patients with chronic diseases that may involve muscle regeneration (Fig. 3) (23).

Zinc transporter (ZIP4). A previous study has indicated that in a mouse pancreatic cancer cachexia model, ZIP4 could stimulate the release of heat shock protein (HSP)70 and HSP90 from the extracellular vesicles to stimulate p38 MAPK-mediated abnormal muscle catabolism (21).

Pyruvate dehydrogenase kinase 4 (PDK4). PDK4 is an important regulator of cellular energy metabolism. High PDK4 and abnormal energetic metabolism were found in the skeletal muscle of colon-26 tumor hosts, as well as in mice fed a diet enriched in Pirinixic acid. Viral-mediated PDK4 overexpression in myotube cultures was sufficient to promote

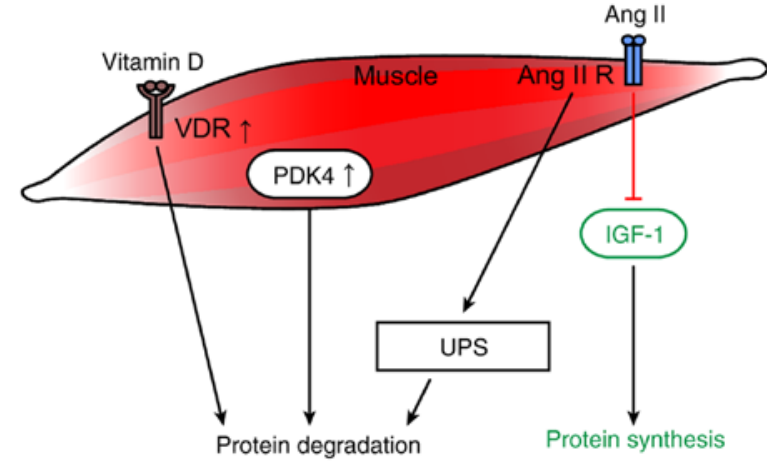

Figure 3. Receptors and substances involved in metabolism that affect muscle protein synthesis and degradation in cancer cachexia. In cancer cachexia, the overexpression of the VDR impairs muscle regeneration and causes protein degradation. Increased PDK4 expression directly promotes cancer cachexia-related changes in muscle metabolism and skeletal muscle atrophy. Furthermore, Ang II activates the UPS to induce protein degradation and inhibits the IGF-1 signaling pathway, thereby interfering with protein synthesis. VDR, vitamin D receptor; Ang II, angiotensin II; R, receptor; UPS, ubiquitin-proteasome system; IGF-1, insulin-like growth factor-1; PDK4, pyruvate dehydrogenase kinase 4.

myofiber shrinkage. On the contrary, blockade of PDK4 was sufficient to restore myotube size in $\mathrm{C} 2 \mathrm{C} 12$ cultures exposed to tumor media. This study by Pin et al (132) was the first to confirm the direct role of PDK4 in promoting cancer-related changes in muscle metabolism and skeletal muscle atrophy through in vitro and in vivo experiments (Fig. 3).

Ang II and IGF-1. Ang II is the main effector molecule of the renin-angiotensin system and increasing evidence has revealed that it also serves an important role in the development of muscle atrophy $(133,134)$. In addition, Ang II has been reported to induce myonuclear apoptosis during muscle atrophy (135).

Ang II was discovered to activate the UPS to induce muscle atrophy by generating ROS and inhibiting the IGF-1 signaling pathway (Fig. 3) (136). Muscle atrophy has been suggested to depend on the impairment of the IGF-1 signaling transduction pathway. Sugiyama et al (19) reported the effects of ghrelin on body weight and muscle catabolism in Ang II-induced cachexia mice. The IGF-1 levels were reduced in the gastrocnemius of the Ang II-treated mice (Fig. 3). Consistently, researchers have reported that ghrelin can improve weight loss and skeletal muscle catabolism in mice treated with Ang II. These effects are thought to be related to the early recovery of IGF-1 mRNA and the improved nutritional status in the skeletal muscle. However, other research has indicated that although the IGF-1 system is downregulated in cancer cachexia, no simple relationship linking IGF-1 and/or MAFbx mRNA expression levels and muscle atrophy could be observed under experimental conditions (Fig. 3) (20).

Clinical research has revealed that compared with patients with cancer without cachexia, those with pre-cachexia or cachexia had upregulated plasma neutrophil-derived protease (NDP) mRNA expression levels and significantly higher Ang II, TGF- $\beta 1$ and C-reactive protein (CRP) levels. These findings suggested that Ang II, TGF $\beta 1$, CRP and NDP may serve as potential circulating biomarkers for cancer cachexia, which may facilitate the early diagnosis and prevention of cancer cachexia (137) 


\section{Treatment of muscle atrophy caused by cancer cachexia}

The pathogenesis of cancer cachexia-associated muscle atrophy is complex and not completely understood. Therefore, multimodal comprehensive treatment should be adopted to delay muscle atrophy caused by cachexia. Related measures include activating the PI3K/AKT/mTOR signaling pathway $(138,139)$, inhibiting the UPS $(140,141)$, proinflammatory factors (142), signal transduction pathways $(53,143)$ and transcription factors (144), and regulating the expression of certain organelles (145) and receptors (146) related to muscle atrophy caused by cancer cachexia.

Activation of the PI3K/AKT/mTOR signaling pathway. The results of multiple studies have suggested that the activation of the PI3K/AKT/mTOR signaling pathway may improve muscle atrophy caused by cancer cachexia. For example, a C26 cancer cell cachexia model in mice was established, and skeletal muscle responses to aerobic exercise and resistance training were compared. Interestingly, neither aerobic nor resistance training prevented tumor-induced weight loss. However, aerobic training maintained the motor function and reduced the inflammatory response in the spleen; therefore, it may slightly improve muscle atrophy by activating the mTOR pathway and exert therapeutic value for patients with cancer cachexia (147). In contrast, resistance training induced the expression of genes related to muscle damage and repair, such as myogenin and IGF-IEb, which might be due to the excessive stress caused by the high resistance load in the tumor-bearing state (147). In addition, Tanaka et al (148) discovered that low-intensity exercise inhibited Yoshida AH130 ascites LC cell-induced cancer cachexia through the skeletal UPS in male Wistar rats. In addition, low-intensity exercise increased the levels of hypoxia-inducible factor- $1 \alpha$ and p-AMPK, which suppressed the loss of muscle mass and the inactivation of mTOR in the soleus muscle. Furthermore, $\mathrm{C} 2 \mathrm{C} 12$ myotubes were cultured in $\mathrm{C} 26$ conditioned medium in vitro, and the pharmacological activity of the myostatin (MSTN) pathway inhibitor IMB0901, which inhibits MSTN promoter activity, MSTN signal transduction and MSTN positive feedback regulation, was determined; the results identified that this compound suppressed muscle atrophy caused by cancer cachexia by inhibiting Ub-mediated proteolysis and enhancing AKT/mTOR-mediated protein synthesis (139).

Inhibition of the UPS. The UPS is the main regulatory mechanism of protein degradation in cancer cachexia-induced muscle atrophy. Previous evidence of potential strategies to protect against skeletal muscle wasting through inhibition of E3 (MuRF-1 and MAFbx) have been summarized $(140,149)$. For example, Levolger et al (141) studied the ability of the ActRIIB and TGF- $\beta$ receptor type-1 inhibitors, SB431542 and GW788388, to prevent muscle atrophy in a C26-CD2F1 cachexia model; it was discovered that the treatment with GW788388 prevented cancer cachexia and downregulated MAFbx.

Another previous study illustrated that valproic acid reduced MAFbx expression levels by inhibiting $\mathrm{C} / \mathrm{EBP} \beta$ binding to the MAFbx promoter, which subsequently decreased skeletal muscle degradation in cancer cachexia mice (150). The traditional Chinese medicine (TCM) Zhimu and Huangbai herb pair was shown to not only inhibit the UPS genes (MuRF1 and FOXO3) associated with muscle atrophy in C57BL/6 colon cancer cachexia model mice, but also activate the IGF-1/AKT and autophagy signaling pathways to facilitate protein synthesis (151). Another study revealed that Baoyuan Jiedu Decoction and Paeonia lactiflora root extract inhibited muscle atrophy in cancer cachexia model mice by downregulating atrogin-1 and MuRF1 expression levels $(140,149)$. Meanwhile, modified Sijunzi decoctions (Zhen-Qi; ZQ-SJZ) have been extensively used to treat cachexia and improve the quality of life of patients with cancer undergoing chemotherapy. The administration of ZQ-SJZ was found to recover tumor- and/or cisplatin-induced body weight loss, as well as the forelimb grip strength and myofiber size. ZQ-SJZ also increased the expression levels of myogenic proteins, such as $\mathrm{MyHC}$ and myogenin, and downregulated the expression levels of the atrophy-related protein atrogin-1 in cisplatin-treated $\mathrm{C} 2 \mathrm{C} 12$ myotubes in vitro (152).

Inhibition of related inflammatory factors. Inflammation is hypothesized to regulate pathways controlling skeletal muscle wasting. A previous study identified that IL-6 and its receptor, as well as JAK2 and STAT3 were significantly attenuated with kimchi. Kimchi was discovered to be a potential option to ameliorate cancer cachexia through its ability to suppress IL-6 and decrease muscle atrophy in a C26 mouse model (142). In addition, in an experimental model of C26-induced cancer cachexia, 20S, 21-epoxy-resibufogenin-3-acetate (ERBA) markedly inhibited body weight loss. ERBA is a specific small molecule with IL-6 receptor antagonist activity (142). Furthermore, another previous study revealed that aerobic interval training enhanced the IL-10/TNF- $\alpha$ ratio, an anti-inflammatory index, and IL-15 expression levels in the skeletal muscle of tumor-bearing mice (153). In vivo trials confirmed that combining exercise training with antioxidant supplements (selenium nanoparticles) may also be a potential strategy to control tumor volume and prevent cachexia in patients with breast cancer (153).

Inhibition of NF- $\kappa B$, STAT3 and MAPK signaling pathways and the transcription factor FOXO. Previous research has reported that important molecules in signaling pathways related to muscle atrophy (NF- $\kappa \mathrm{B}, \mathrm{MAPK}$ and FOXO), proteolytic markers (Ub ligases and proteasomes), autophagy markers (p62, Beclin-1 and microtubule-associated protein 1A/1B light chain 3B) and myostatin levels were upregulated, while regeneration and metabolic markers $(\mathrm{MyoD}, \mathrm{mTOR}, \mathrm{AKT}$ and peroxisome proliferator-activated receptor $\gamma$ coactivator $1-\alpha)$ were decreased in cachexia. These changes were attenuated by the administration of formoterol in cachexia model rats (154). Moreover, coix seed oil ameliorated cancer cachexia by counteracting muscle loss and fat lipolysis in an LLC cachexia model in C57BL/6 mice through the regulation of the NF- $\kappa \mathrm{B} / \mathrm{MuRF} 1$ and AMPK/hormone sensitive lipase pathways (143).

Cryptotanshinone prevented muscle wasting in cancer cachexia through STAT3 inhibition, therefore it was suggested to be a promising candidate drug for the treatment of cancer 
cachexia (53). Sunitinib was able to alleviate the overactivation of the STAT3 and MuRF1 signaling pathways, which prevented body weight loss and muscle wasting during cancer cachexia (155). In addition, an in vivo study reported that although pyrrolidine dithiocarbamate (PDTC) did not reduce the tumor volume in a $\mathrm{C} 26$ xenograft mouse model, it reduced cancer cachexia symptoms. In addition, in vitro studies demonstrated that PDTC inhibited muscle atrophy and lipolysis in an in vitro cell model induced by TNF- $\alpha$ and C26 tumor cell supernatant, and impeded the atrophy of C2C12-differentiated myotubes by downregulating MyoD and upregulating MuRF1 expression levels. Moreover, in addition to inhibiting NF- $\kappa \mathrm{B}$ signaling, PDTC inhibited p38 MAPK signaling and affected skeletal muscle protein synthesis by activating AKT signaling (156). In another study, the expression levels of the transcription factor FOXO were upregulated in 85As2-induced cachectic model rats, and the increased FOXO expression levels were considered to be associated with the increased expression of atrogin-1 and MuRF1. Notably, the oral administration of rikkunshito, a traditional Japanese medicine, substantially ameliorated the presence of cancer cachexia (144).

These findings provided further possible molecular mechanisms for the targeted suppression of muscle atrophy induced by cancer cachexia.

Regulation of the expression of components in the mitochondria (Mfn2). Mfn2 is highly expressed in muscle cells, and its function is diminished by disruptions in the mitochondrial network, which is essential for maintaining normal mitochondrial function (145). Clinical studies have reported that Mfn2 expression levels were downregulated in the rectus abdominis of patients with cancer cachexia (24). Further evidence indicated that Mfn2 overexpression improved TNF- $\alpha$-induced $\mathrm{C} 2 \mathrm{C} 12$ cell muscle atrophy in vitro. Moreover, in vivo experiments demonstrated that Mfn2 overexpression in the gastrocnemius muscle partially reduced gastrocnemius muscle loss caused by cachexia. Overall, these findings suggested that Mfn2 may be involved in cachexia-induced muscle loss and may be a potential target for cachexia treatment (145).

Regulation of Ang II and $\beta 2$ receptor agonism. Ang-(1-7) has been demonstrated to counteract the skeletal muscle atrophy induced by Ang II through a mechanism that is dependent on the Mas receptor and involves AKT activity (135). In an in vivo assay, the deletion of NADPH oxidase 2 prevented Ang II-induced skeletal muscle atrophy by improving the balance between protein synthesis and degradation (157). Formoterol is a highly potent $\beta 2$-adrenoceptor selective agonist and a muscle growth promoter in numerous species of animal (146). Myostatin/activin inhibition reversed skeletal muscle loss and prolonged survival in tumor-bearing animals (146). In an LLC cachexia-induced muscle atrophy model, Toledo et al (146) discovered that the combination of formoterol and the soluble myostatin receptor, ActRIIB, effectively reversed the muscle wasting associated with cancer cachexia, which provided further clinical evidence for potential treatment options for cancer cachexia-related muscle wasting.
Others. In addition, treatment regimens should include proper nutritional plans, psychological intervention and to achieve synergistic effects and change the abnormal cachexia metabolism. Although current research has demonstrated that reversing the progression of cachexia with nutritional support alone is difficult, increasing nutrient intake was found to somewhat delay the progression of cachexia and improve the quality of life (158). Previous studies have investigated the need for nutritional support among patients with advanced cancer in the palliative care environment; patients with cancer cachexia had a greater need for nutritional support and desired additional support from medical staff when the negative effects of cachexia become apparent, of which adequate nutrition cannot be guaranteed by oral nutritional supplements (159).

Furthermore, patients with cancer cachexia often develop complications due to the tumor itself or tumor-related effects. Several patients with cancer face psychological burdens or have other medical conditions and experience psychological symptoms such as fear, anxiety and depression (160). McClement (160) proposed providing psychosocial support for such patients and their families. Moreover, nurses must understand the psychological impact of anorexia and cachexia on affected individuals and suggest interventions that the medical team can implement to address these issues. Continuous research has been recommended to obtain a more complete understanding of the psychological aspects of the patient experience.

The treatment effectiveness of chemical drugs has not been established by existing cachexia guidelines. In a TCM study, a large portion of patients with cancer cachexia were diagnosed with spleen deficiency syndrome and treated with tonifying TCM, which produced clinical benefits (161). Oral administration of atractylenolide I $(20 \mathrm{mg} / \mathrm{kg}$ per day for 30 days) significantly ameliorated the reduction in body weight and atrophy of the muscles, spleen and thymus in mice with spleen deficiency and cachexia (161). Clinical trials on the efficacy and safety of the Yukgunja-Tang herbal mixture in the treatment of cancer anorexia are also underway (162).

\section{Conclusions}

In conclusion, cancer cachexia is a metabolic syndrome associated with malignant tumor progression, which involves multiple mechanisms that cause muscle atrophy. The pathogenesis is extremely complex and previous studies have produced inconsistent results. Currently, no single drug that can effectively reverse cachexia is included in clinical guidelines. Therefore, the lack of treatment options combined with the complicated pathogenesis necessitate the development of combination therapeutics that target multiple pathways and targets.

In the future, it is predicted that cancer cachexia will become a research hotspot in the field of cancer research; this will help to further elucidate the pathogenesis of cachexia, initiate the development of clinical trials and the emergence of more effective drugs to reduce muscle cachexia associated with cancer, and thereby improve the quality of life of patients and extend patient survival. 


\section{Acknowledgements}

Not applicable.

\section{Funding}

No funding was received.

\section{Availability of data and materials}

Not applicable.

\section{Authors' contributions}

WY, JH and WG conceptualized and designed the review. HW, YW, ZD, YL, WW and QW conducted the literature review and compiled the information. WY and $\mathrm{JH}$ wrote the manuscript. WG revised the manuscript. All authors read and approved the final manuscript.

\section{Ethics approval and consent to participate}

Not applicable.

\section{Patient consent for publication}

Not applicable.

\section{Competing interests}

The authors declare that they have no competing interests.

\section{References}

1. Fearon K, Strasser F, Anker SD, Bosaeus I, Bruera E, Fainsinger RL, Jatoi A, Loprinzi C, MacDonald N, Mantovani G, et al: Definition and classification of cancer cachexia: An international consensus. Lancet Oncol 12: 489-495, 2011.

2. Blum D, Stene GB, Solheim TS, Fayers P, Hjermstad MJ, Baracos VE, Fearon K, Strasser F and Kaasa S; Euro-Impact: Validation of the consensus-definition for cancer cachexia and evaluation of a classification model-a study based on data from an international multicentre project (EPCRC-CSA). Ann Oncol 25: $1635-1642,2014$

3. Baumgartner RN, Koehler KM, Gallagher D, Romero L, Heymsfield SB, Ross RR, Garry PJ and Lindeman RD: Epidemiology of sarcopenia among the elderly in New Mexico. Am J Epidemiol 147: 755-763, 1998.

4. Emery PW, Edwards RH, Rennie MJ, Souhami RL and Halliday D: Protein synthesis in muscle measured in vivo in cachectic patients with cancer. Br Med J (Clin Res Ed) 289: 584-586, 1984.

5. Warnold I, Lundholm K and Schersten T: Energy balance and body composition in cancer patients. Cancer Res 38: 1801-1807, 1978.

6. Chang VT, Xia Q and Kasimis B: The functional assessment of anorexia/cachexia therapy (FAACT) appetite scale in veteran cancer patients. J Support Oncol 3: 377-382, 2005.

7. Martin L, Birdsell L, Macdonald N, Reiman T, Clandinin MT, McCargar LJ, Murphy R, Ghosh S, Sawyer MB and Baracos VE: Cancer cachexia in the age of obesity: Skeletal muscle depletion is a powerful prognostic factor, independent of body mass index. J Clin Oncol 31: 1539-1547, 2013.

8. Dewys WD, Begg C, Lavin PT, Band PR, Bennett JM, Bertino JR, Cohen MH, Douglass HO Jr, Engstrom PF, Ezdinli EZ, et al: Prognostic effect of weight loss prior to chemotherapy in cancer patients. Eastern Cooperative Oncology Group. Am J Med 69: 491-497, 1980
9. Dunne RF, Roussel B, Culakova E, Pandya C, Fleming FJ, Hensley B, Magnuson AM, Loh KP, Gilles M, Ramsdale E, et al: Characterizing cancer cachexia in the geriatric oncology population. J Geriatr Oncol 10: 415-419, 2019.

10. Sadeghi M, Keshavarz-Fathi M, Baracos V, Arends J, Mahmoudi M and Rezaei N: Cancer cachexia: Diagnosis, assessment, and treatment. Crit Rev Oncol Hematol 127: 91-104, 2018.

11. Tazi E and Errihani H: Treatment of cachexia in oncology. Indian J Palliat Care 16: 129-137, 2010.

12. Li YP, Chen Y, John J, Moylan J, Jin B, Mann DL and Reid MB: TNF-alpha acts via p38 MAPK to stimulate expression of the ubiquitin ligase atrogin1/MAFbx in skeletal muscle. FASEB J 19: 362-370, 2005.

13. Bonetto A, Aydogdu T, Jin X, Zhang Z, Zhan R, Puzis L, Koniaris LG and Zimmers TA: JAK/STAT3 pathway inhibition blocks skeletal muscle wasting downstream of IL-6 and in experimental cancer cachexia. Am J Physiol Endocrinol Metab 303: E410-421, 2012.

14. Braun TP, Zhu X, Szumowski M, Scott GD, Grossberg AJ, Levasseur PR, Graham K, Khan S, Damaraju S, Colmers WF, et al: Central nervous system inflammation induces muscle atrophy via activation of the hypothalamic-pituitary-adrenal axis. J Exp Med 208: 2449-2463, 2011.

15. Judge SM, Wu CL, Beharry AW, Roberts BM, Ferreira LF, Kandarian SC and Judge AR: Genome-wide identification of FoxO-dependent gene networks in skeletal muscle during C26 cancer cachexia. BMC Cancer 14: 997, 2014.

16. Schmitt TL, Martignoni ME, Bachmann J, Fechtner K, Friess H, Kinscherf R and Hildebrandt W: Activity of the Akt-dependent anabolic and catabolic pathways in muscle and liver samples in cancer-related cachexia. J Mol Med (Berl) 85: 647-654, 2007.

17. Silva KA, Dong J, Dong Y, Dong Y, Schor N, Tweardy DJ, Zhang $\mathrm{L}$ and Mitch WE: Inhibition of Stat 3 activation suppresses caspase- 3 and the ubiquitin-proteasome system, leading to preservation of muscle mass in cancer cachexia. J Biol Chem 290: 11177-11187, 2015.

18. Murton AJ, Maddocks M, Stephens FB, Marimuthu K, England R and Wilcock A: Consequences of late-stage non-small-cell lung cancer cachexia on muscle metabolic processes. Clin Lung Cancer 18: e1-e11, 2017.

19. Sugiyama M, Yamaki A, Furuya M, Inomata N, Minamitake Y, Ohsuye $\mathrm{K}$ and Kangawa K: Ghrelin improves body weight loss and skeletal muscle catabolism associated with angiotensin II-induced cachexia in mice. Regul Pept 178: 21-28, 2012.

20. Costelli P, Muscaritoli M, Bossola M, Penna F, Reffo P, Bonetto A Busquets S, Bonelli G, Lopez-Soriano FJ, Doglietto GB, et al: IGF-1 is downregulated in experimental cancer cachexia. Am J Physiol Regul Integr Comp Physiol 291: R674-683, 2006.

21. Yang J, Zhang Z, Zhang Y, Ni X, Zhang G, Cui X, Liu M, Xu C, Zhang Q, Zhu H, et al: ZIP4 promotes muscle wasting and cachexia in mice with orthotopic pancreatic tumors by stimulating RAB27B-regulated release of extracellular vesicles from cancer cells. Gastroenterology 156: 722-734.e6, 2019.

22. Pin F, Minero VG, Penna F, Muscaritoli M, De Tullio R, Baccino FM and Costelli P: Interference with $\mathrm{Ca}^{2+}$-dependent proteolysis does not alter the course of muscle wasting in experimental cancer cachexia. Front Physiol 8: 213, 2017.

23. Camperi A, Pin F, Costamagna D, Penna F, Menduina ML, Aversa Z, Zimmers T, Verzaro R, Fittipaldi R, Caretti G, et al: Vitamin D and VDR in cancer cachexia and muscle regeneration. Oncotarget 8: 21778-21793, 2017.

24. Marzetti E, Lorenzi M, Landi F, Picca A, Rosa F, Tanganelli F, Galli M, Doglietto GB, Pacelli F, Cesari M, et al: Altered mitochondrial quality control signaling in muscle of old gastric cancer patients with cachexia. Exp Gerontol 87: 92-99, 2017.

25. Williams A, Sun X, Fischer JE and Hasselgren PO: The expression of genes in the ubiquitin-proteasome proteolytic pathway is increased in skeletal muscle from patients with cancer. Surgery 126: 744-750, 1999.

26. Doyle A, Zhang G, Abdel Fattah EA, Eissa NT and Li YP: Toll-like receptor 4 mediates lipopolysaccharide-induced muscle catabolism via coordinate activation of ubiquitin-proteasome and autophagy-lysosome pathways. FASEB J 25: 99-110, 2011.

27. Furuno K and Goldberg AL: The activation of protein degradation in muscle by $\mathrm{Ca} 2+$ or muscle injury does not involve a lysosomal mechanism. Biochem J 237: 859-864, 1986.

28. Lecker SH, Solomon V, Mitch WE and Goldberg AL: Muscle protein breakdown and the critical role of the ubiquitinproteasome pathway in normal and disease states. J Nutr 129 (Suppl 1): S227-S237, 1999. 
29. White JP, Puppa MJ, Gao S, Sato S, Welle SL and Carson JA Muscle mTORC1 suppression by IL-6 during cancer cachexia: A role for AMPK. Am J Physiol Endocrinol Metab 304: E1042-E1052, 2013.

30. Li YP, Schwartz RJ, Waddell ID, Holloway BR and Reid MB: Skeletal muscle myocytes undergo protein loss and reactive oxygen-mediated NF-kappaB activation in response to tumor necrosis factor alpha. FASEB J 12: 871-880, 1998.

31. Bohnert KR, Gallot YS, Sato S, Xiong G, Hindi SM and Kumar A: Inhibition of ER stress and unfolding protein response pathways causes skeletal muscle wasting during cancer cachexia. FASEB J 30: 3053-3068, 2016

32. Fontes-Oliveira CC, Busquets S, Toledo M, Penna F, Paz Aylwin M, Sirisi S, Silva AP, Orpí M, García A, Sette A, et al Mitochondrial and sarcoplasmic reticulum abnormalities in cancer cachexia: Altered energetic efficiency? Biochim Biophys Acta 1830: 2770-2778, 2013.

33. Mondello P, Mian M, Aloisi C, Fama F, Mondello S and Pitini V: Cancer cachexia syndrome: Pathogenesis, diagnosis, and new therapeutic options. Nutr Cancer 67: 12-26, 2015.

34. Hershko A and Ciechanover A: The ubiquitin system. Annu Rev Biochem 67: 425-479, 1998.

35. Hershko A and Ciechanover A: Mechanisms of intracellular protein breakdown. Annu Rev Biochem 51: 335-364, 1982.

36. Haas AL and Rose IA: The mechanism of ubiquitin activating enzyme. A kinetic and equilibrium analysis. J Biol Chem 257: 10329-10337, 1982.

37. Hershko A, Heller H, Elias S and Ciechanover A: Components of ubiquitin-protein ligase system. Resolution, affinity purification, and role in protein breakdown. J Biol Chem 258: 8206-8214, 1983.

38. Hershko A: The ubiquitin pathway for protein degradation. Trends Biochem Sci 16: 265-268, 1991.

39. Reiss Y, Heller $\mathrm{H}$ and Hershko A: Binding sites of ubiquitin-protein ligase. Binding of ubiquitin-protein conjugates and of ubiquitin-carrier protein. J Biol Chem 264: 10378-10383, 1989.

40. Voges D, Zwickl P and Baumeister W: The 26S proteasome: A molecular machine designed for controlled proteolysis. Annu Rev Biochem 68: 1015-1068, 1999.

41. Glickman MH and Ciechanover A: The ubiquitin-proteasome proteolytic pathway: Destruction for the sake of construction. Physiol Rev 82: 373-428, 2002

42. Rom O and Reznick AZ: The role of E3 ubiquitin-ligases MuRF-1 and MAFbx in loss of skeletal muscle mass. Free Radic Biol Med 98: 218-230, 2016.

43. Cai D, Frantz JD, Tawa NE Jr, Melendez PA, Oh BC, Lidov HG, Hasselgren PO, Frontera WR, Lee J, Glass DJ and Shoelson SE: IKKbeta/NF-kappaB activation causes severe muscle wasting in mice. Cell 119: 285-298, 2004.

44. Li W, Moylan JS, Chambers MA, Smith J and Reid MB: Interleukin-1 stimulates catabolism in $\mathrm{C} 2 \mathrm{C} 12$ myotubes. Am J Physiol Cell Physiol 297: C706-C714, 2009.

45. McClung JM, Judge AR, Powers SK and Yan Z: p38 MAPK links oxidative stress to autophagy-related gene expression in cachectic muscle wasting. Am J Physiol Cell Physiol 298: C542-C549, 2010

46. Kaisari S, Rom O, Aizenbud D and Reznick AZ: Involvement of NF- $\mathrm{NB}$ and muscle specific E3 ubiquitin ligase MuRF1 in cigarette smoke-induced catabolism in $\mathrm{C} 2$ myotubes. Adv Exp Med Biol 788: 7-17, 2013

47. Patel HJ and Patel BM: TNF- $\alpha$ and cancer cachexia: Molecular insights and clinical implications. Life Sci 170: 56-63, 2017.

48. Parajuli P, Kumar S, Loumaye A, Singh P, Eragamreddy S, Nguyen TL, Ozkan S, Razzaque MS, Prunier C, Thissen JP and Atfi A: Twist 1 activation in muscle progenitor cells causes muscle loss akin to cancer cachexia. Dev Cell 45: 712-725.e6, 2018.

49. Fry CS, Nayeem SZ, Dillon EL, Sarkar PS, Tumurbaatar B Urban RJ, Wright TJ, Sheffield-Moore M, Tilton RG and Choudhary S: Glucocorticoids increase skeletal muscle NF- $\kappa B$ inducing kinase (NIK): Links to muscle atrophy. Physiol Rep 4: 2016.

50. Gallot YS, Durieux AC, Castells J, Desgeorges MM, Vernus B, Plantureux L, Rémond D, Jahnke VE, Lefai E, Dardevet D, et al: Myostatin gene inactivation prevents skeletal muscle wasting in cancer. Cancer Res 74: 7344-7356, 2014.

51. Bédard N, Jammoul S, Moore T, Wykes L, Hallauer PL, Hastings KE, Stretch C, Baracos V, Chevalier S, Plourde M, et al Inactivation of the ubiquitin-specific protease 19 deubiquitinating enzyme protects against muscle wasting. FASEB J 29: 3889-3898, 2015
52. Lee H, Lee SJ, Bae GU, Baek NI and Ryu JH: Canadine from corydalis turtschaninovii stimulates myoblast differentiation and protects against myotube atrophy. Int J Mol Sci 18: 2748, 2017.

53. Chen L, Yang Q, Zhang H, Wan L, Xin B, Cao Y, Zhang J and Guo C: Cryptotanshinone prevents muscle wasting in CT26-induced cancer cachexia through inhibiting STAT3 signaling pathway. J Ethnopharmacol 260: 113066, 2020.

54. Chong SW, Nguyet LM, Jiang YJ and Korzh V: The chemokine Sdf-1 and its receptor Cxcr4 are required for formation of muscle in zebrafish. BMC Dev Biol 7: 54, 2007.

55. Melchionna R, Di Carlo A, De Mori R, Cappuzzello C, Barberi L, Musarò A, Cencioni C, Fujii N, Tamamura H, Crescenzi M, et al: Induction of myogenic differentiation by SDF-1 via CXCR4 and CXCR7 receptors. Muscle Nerve 41: 828-835, 2010.

56. Bobadilla M, Sainz N, Abizanda G, Orbe J, Rodriguez JA, Páramo JA, Prósper F and Pérez-Ruiz A: The CXCR4/SDF1 axis improves muscle regeneration through MMP-10 activity. Stem Cells Dev 23: 1417-1427, 2014.

57. Martinelli GB, Olivari D, Re Cecconi AD, Talamini L, Ottoboni L, Lecker SH, Stretch C, Baracos VE, Bathe OF, Resovi A, et al: Activation of the SDF1/CXCR4 pathway retards muscle atrophy during cancer cachexia. Oncogene 35: 6212-6222, 2016.

58. Winbanks CE, Murphy KT, Bernardo BC, Qian H, Liu Y, Sepulveda PV, Beyer C, Hagg A, Thomson RE, Chen JL, et al: Smad7 gene delivery prevents muscle wasting associated with cancer cachexia in mice. Sci Transl Med 8: 348ra398, 2016

59. Stephens NA, Gallagher IJ, Rooyackers O, Skipworth RJ, Tan BH, Marstrand T, Ross JA, Guttridge DC, Lundell L, Fearon KC and Timmons JA: Using transcriptomics to identify and validate novel biomarkers of human skeletal muscle cancer cachexia. Genome Med 2: 1, 2010.

60. Eskiler GG, Bezdegumeli E, Ozman Z, Ozkan AD, Bilir C, Kucukakca BN, Ince MN, Men AY, Aktas O, Horoz YE, et al: IL-6 mediated JAK/STAT3 signaling pathway in cancer patients with cachexia. Bratisl Lek Listy 66: 819-826, 2019.

61. Pin F, Barreto R, Kitase Y, Mitra S, Erne CE, Novinger LJ, Zimmers TA, Couch ME, Bonewald LF and Bonetto A: Growth of ovarian cancer xenografts causes loss of muscle and bone mass: A new model for the study of cancer cachexia. J Cachexia Sarcopenia Muscle 9: 685-700, 2018

62. Grabiec AM, Korchynskyi O, Tak PP and Reedquist KA: Histone deacetylase inhibitors suppress rheumatoid arthritis fibroblast-like synoviocyte and macrophage IL- 6 production by accelerating mRNA decay. Ann Rheum Dis 71: 424-431, 2012.

63. Ma F, Li Y, Jia L, Han Y, Cheng J, Li H, Qi Y and Du J: Macrophage-stimulated cardiac fibroblast production of IL-6 is essential for TGF $\beta / \mathrm{Smad}$ activation and cardiac fibrosis induced by angiotensin II. PLoS One 7: e35144, 2012.

64. Miki S, Iwano M, Miki Y, Yamamoto M, Tang B, Yokokawa K, Sonoda T, Hirano T and Kishimoto T: Interleukin-6 (IL-6) functions as an in vitro autocrine growth factor in renal cell carcinomas. FEBS Lett 250: 607-610, 1989.

65. Iwase S, Murakami T, Saito Y and Nakagawa K: Steep elevation of blood interleukin-6 (IL-6) associated only with late stages of cachexia in cancer patients. Eur Cytokine Netw 15: 312-316, 2004

66. Fujimoto-Ouchi K, Onuma E, Shirane M, Mori K and Tanaka Y: Capecitabine improves cancer cachexia and normalizes IL-6 and PTHrP levels in mouse cancer cachexia models. Cancer Chemother Pharmacol 59: 807-815, 2007.

67. White JP, Baltgalvis KA, Puppa MJ, Sato S, Baynes JW and Carson JA: Muscle oxidative capacity during IL-6-dependent cancer cachexia. Am J Physiol Regul Integr Comp Physiol 300: R201-R211, 2011.

68. Op den Kamp CM, Gosker HR, Lagarde S, Tan DY, Snepvangers FJ, Dingemans AM, Langen RC and Schols AM: Preserved muscle oxidative metabolic phenotype in newly diagnosed non-small cell lung cancer cachexia. J Cachexia Sarcopenia Muscle 6: 164-173, 2015.

69. Siddiqui RA and Williams JF: Tentative identification of the toxohormones of cancer cachexia: Roles of vasopressin, prostaglandin E2 and cachectin-TNF. Biochem Int 20: 787-797, 1990.

70. Llovera M, García-Martínez C, López-Soriano J, Carbó N, Agell N, López-Soriano FJ and Argiles JM: Role of TNF receptor 1 in protein turnover during cancer cachexia using gene knockout mice. Mol Cell Endocrinol 142: 183-189, 1998.

71. Powrozek T, Mlak R, Brzozowska A, Mazurek M, Golebiowski P and Malecka-Massalska T: Relationship between TNF- $\alpha$ $-1031 \mathrm{~T} / \mathrm{C}$ gene polymorphism, plasma level of TNF- $\alpha$, and risk of cachexia in head and neck cancer patients. J Cancer Res Clin Oncol 144: 1423-1434, 2018. 
72. Llovera M, García-Martínez C, Agell N, López-Soriano FJ and Argilés JM: TNF can directly induce the expression of ubiquitin-dependent proteolytic system in rat soleus muscles. Biochem Biophys Res Commun 230: 238-241, 1997.

73. Matsuyama T, Ishikawa T, Okayama T, Oka K, Adachi S, Mizushima K, Kimura R, Okajima M, Sakai H, Sakamoto N, et al: Tumor inoculation site affects the development of cancer cachexia and muscle wasting. Int J Cancer 137: 2558-2565, 2015.

74. Mu X, Agarwal R, March D, Rothenberg A, Voigt C, Tebbets J, Huard $J$ and Weiss $K$ : Notch signaling mediates skeletal muscle atrophy in cancer cachexia caused by osteosarcoma. Sarcoma 2016: 3758162, 2016.

75. Cannon T, Shores C, Yin X, Dahlman J, Guttridge D, Lai V, George J, Buzkova P and Couch M: Immunocompetent murine model of cancer cachexia for head and neck squamous cell carcinoma. Head Neck 30: 320-326, 2008.

76. Mi L, Lin J, Zheng H, Xu X, Zhang J and Zhang D: Bacterial translocation contributes to cachexia from locally advanced gastric cancer. Hepatogastroenterology 59: 2348-2351, 2012.

77. Kumar S, Kishimoto H, Chua HL, Badve S, Miller KD, Bigsby RM and Nakshatri H: Interleukin-1 alpha promotes tumor growth and cachexia in MCF-7 xenograft model of breast cancer. Am J Pathol 163: 2531-2541, 2003.

78. Zheng R, Huang S, Zhu J, Lin W, Xu H and Zheng X: Leucine attenuates muscle atrophy and autophagosome formation by activating PI3K/AKT/mTOR signaling pathway in rotator cuff tears. Cell Tissue Res 378: 113-125, 2019.

79. Lee S, Kim MB, Kim C and Hwang JK: Whole grain cereal attenuates obesity-induced muscle atrophy by activating the PI3K/Akt pathway in obese C57BL/6N mice. Food Sci Biotechnol 27 159-168, 2018

80. Ma XM and Blenis J: Molecular mechanisms of mTOR-mediated translational control. Nat Rev Mol Cell Biol 10: 307-318, 2009.

81. Jiang BH, Aoki M, Zheng JZ, Li J and Vogt PK: Myogenic signaling of phosphatidylinositol 3-kinase requires the serine-threonine kinase Akt/protein kinase B. Proc Natl Acad Sci USA 96: 2077-2081, 1999.

82. Price DJ, Grove JR, Calvo V, Avruch J and Bierer BE: Rapamycin-induced inhibition of the 70 -kilodalton S6 protein kinase. Science 257: 973-977, 1992.

83. Chung J, Kuo CJ, Crabtree GR and Blenis J: Rapamycin-FKBP specifically blocks growth-dependent activation of and signaling by the $70 \mathrm{kd}$ S6 protein kinases. Cell 69: 1227-1236, 1992.

84. Lin TA, Kong X, Saltiel AR, Blackshear PJ and Lawrence JC Jr: Control of PHAS-I by insulin in 3T3-L1 adipocytes. Synthesis, degradation, and phosphorylation by a rapamycin-sensitive and mitogen-activated protein kinase-independent pathway. J Biol Chem 270: 18531-18538, 1995.

85. Graves LM, Bornfeldt KE, Argast GM, Krebs EG, Kong X, Lin TA and Lawrence JC Jr: cAMP- and rapamycin-sensitive regulation of the association of eukaryotic initiation factor $4 \mathrm{E}$ and the translational regulator PHAS-I in aortic smooth muscle cells. Proc Natl Acad Sci USA 92: 7222-7226, 1995.

86. Stitt TN, Drujan D, Clarke BA, Panaro F, Timofeyva Y, Kline WO, Gonzalez M, Yancopoulos GD and Glass D: The IGF-1/PI3K/Akt pathway prevents expression of muscle atrophy-induced ubiquitin ligases by inhibiting FOXO transcription factors. Mol Cell 14 395-403, 2004

87. Sandri M, Sandri C, Gilbert A, Skurk C, Calabria E, Picard A, Walsh K, Schiaffino S, Lecker SH and Goldberg AL: Foxo transcription factors induce the atrophy-related ubiquitin ligase atrogin-1 and cause skeletal muscle atrophy. Cell 117: 399-412, 2004

88. Manne ND, Lima M, Enos RT, Wehner P, Carson JA and Blough E: Altered cardiac muscle mTOR regulation during the progression of cancer cachexia in the ApcMin/+ mouse. Int J Oncol 42: 2134-2140, 2013

89. Ge Y, Wu AL, Warnes C, Liu J, Zhang C, Kawasome H, Terada N, Boppart MD, Schoenherr CJ and Chen J: mTOR regulates skeletal muscle regeneration in vivo through kinase-dependent and kinase-independent mechanisms. Am J Physiol Cell Physiol 297: C1434-C1444, 2009.

90. Zimmers TA, Fishel ML and Bonetto A: STAT3 in the systemic inflammation of cancer cachexia. Semin Cell Dev Biol 54: 28-41, 2016.

91. Bonetto A, Aydogdu T, Kunzevitzky N, Guttridge DC, Khuri S, Koniaris LG and Zimmers TA: STAT3 activation in skeletal muscle links muscle wasting and the acute phase response in cancer cachexia. PLoS One 6: e22538, 2011.
92. Ma JF, Sanchez BJ, Hall DT, Tremblay AK, Di Marco S and Gallouzi IE: STAT3 promotes IFN $\gamma / T N F \alpha$-induced muscle wasting in an NF- $\kappa \mathrm{B}$-dependent and IL-6-independent manner. EMBO Mol Med 9: 622-637, 2017.

93. Ghosh S and Karin M: Missing pieces in the NF-kappaB puzzle. Cell 109 (Suppl 1): S81-S96, 2002.

94. Hayden MS and Ghosh S: NF-kappaB in immunobiology. Cell Res 21: 223-244, 2011.

95. Thoma A and Lightfoot AP: NF-kB and inflammatory cytokine signalling: Role in skeletal muscle atrophy. Adv Exp Med Biol 1088: 267-279, 2018

96. Di Marco S, Mazroui R, Dallaire P, Chittur S, Tenenbaum SA Radzioch D, Marette A and Gallouzi IE: NF-kappa B-mediated MyoD decay during muscle wasting requires nitric oxide synthase mRNA stabilization, HuR protein, and nitric oxide release. Mol Cell Biol 25: 6533-6545, 2005.

97. Cuenda A and Rousseau S: p38 MAP-kinases pathway regulation, function and role in human diseases. Biochim Biophys Acta 1773: 1358-1375, 2007.

98. Kim J, Won KJ, Lee HM, Hwang BY, Bae YM, Choi WS, Song H, Lim KW, Lee CK and Kim B: p38 MAPK participates in muscle-specific RING finger 1-mediated atrophy in cast-immobilized rat gastrocnemius muscle. Korean J Physiol Pharmacol 13: 491-496, 2009.

99. Ryu Y, Lee D, Jung SH, Lee KJ, Jin H, Kim SJ, Lee HM, Kim B and Won KJ: Sabinene prevents skeletal muscle atrophy by inhibiting the MAPK-MuRF-1 pathway in rats. Int J Mol Sci 20: 4955, 2019.

100. Belova SP, Mochalova EP, Kostrominova TY, Shenkman BS and Nemirovskaya TL: P38 $\alpha$-MAPK signaling inhibition attenuates soleus atrophy during early stages of muscle unloading. Int J Mol Sci 21: 2756, 2020.

101. Girven M, Dugdale HF, Owens DJ, Hughes DC, Stewart CE and Sharples AP: l-glutamine improves skeletal muscle cell differentiation and prevents myotube atrophy after cytokine $(T N F-\alpha)$ stress via reduced p38 MAPK signal transduction. J Cell Physiol 231: 2720-2732, 2016.

102. Morales MG, Olguin H, Di Capua G, Brandan E, Simon F and Cabello-Verrugio C: Endotoxin-induced skeletal muscle wasting is prevented by angiotensin-(1-7) through a 38 MAPK-dependent mechanism. Clin Sci (Lond) 129: 461-476, 2015.

103. O'Neill BT, Bhardwaj G, Penniman CM, Krumpoch MT, Suarez Beltran PA, Klaus K, Poro K, Li M, Pan H, Dreyfuss JM, et al: FoxO transcription factors are critical regulators of diabetes-related muscle atrophy. Diabetes 68: 556-570, 2019.

104. Liu CM, Yang Z, Liu CW, Wang R, Tien P, Dale R and Sun LQ: Effect of RNA oligonucleotide targeting Foxo-1 on muscle growth in normal and cancer cachexia mice. Cancer Gene Ther 14: 945-952, 2007.

105. Blackwell TA, Cervenka I, Khatri B, Brown JL, Rosa-Caldwell ME, Lee DE, Perry RA Jr, Brown LA, Haynie WS, Wiggs MP, et al: Transcriptomic analysis of the development of skeletal muscle atrophy in cancer-cachexia in tumor-bearing mice. Physiol Genomics 50: 1071-1082, 2018.

106. Marchildon F, Lamarche E, Lala-Tabbert N, St-Louis C and Wiper-Bergeron N: Expression of CCAAT/enhancer binding protein beta in muscle satellite cells inhibits myogenesis in cancer cachexia. PLoS One 10: e0145583, 2015.

107. Freire PP, Fernandez GJ, Cury SS, de Moraes D, Oliveira JS, de Oliveira G, Dal-Pai-Silva M, Dos Reis PP and Carvalho RF: The pathway to cancer cachexia: MicroRNA-regulated networks in muscle wasting based on integrative meta-analysis. Int J Mol Sci 20: 2019

108. Lee DE, Brown JL, Rosa-Caldwell ME, Blackwell TA, Perry RA Jr, Brown LA, Khatri B, Seo D, Bottje WG, Washington TA, et al: Cancer cachexia-induced muscle atrophy: Evidence for alterations in microRNAs important for muscle size. Physiol Genomics 49: 253-260, 2017.

109. Sandri M: Autophagy in health and disease. 3. Involvement of autophagy in muscle atrophy. Am J Physiol Cell Physiol 298 C1291-C1297, 2010

110. Bargiela A, Cerro-Herreros E, Fernandez-Costa JM, Vilchez JJ, Llamusi B and Artero R: Increased autophagy and apoptosis contribute to muscle atrophy in a myotonic dystrophy type 1 Drosophila model. Dis Model Mech 8: 679-690, 2015.

111. Pettersen K, Andersen S, Degen S, Tadini V, Grosjean J, Hatakeyama S, Tesfahun AN, Moestue S, Kim J, Nonstad U, et al: Cancer cachexia associates with a systemic autophagy-inducing activity mimicked by cancer cell-derived IL-6 trans-signaling. Sci Rep 7: 2046, 2017. 
112. Penna F, Ballarò R, Martinez-Cristobal P, Sala D, Sebastian D, Busquets S, Muscaritoli M, Argilés JM, Costelli P and Zorzano A: Autophagy exacerbates muscle wasting in cancer cachexia and impairs mitochondrial function. J Mol Biol 431: 2674-2686, 2019.

113. Pettersen K, Andersen S, van der Veen A, Nonstad U, Hatakeyama S, Lambert C, Lach-Trifilieff E, Moestue S, Kim J, Grønberg BH, et al: Autocrine activin A signalling in ovarian cancer cells regulates secretion of interleukin 6, autophagy, and cachexia. J Cachexia Sarcopenia Muscle 11: 195-207, 2020.

114. Mirza KA and Tisdale MJ: Role of $\mathrm{Ca}^{2+}$ in proteolysis-inducing factor (PIF)-induced atrophy of skeletal muscle. Cell Signal 24 2118-2122, 2012.

115. Kozutsumi Y, Segal M, Normington K, Gething MJ and Sambrook J: The presence of malfolded proteins in the endoplasmic reticulum signals the induction of glucose-regulated proteins. Nature 332: 462-464, 1988

116. Bohnert KR, McMillan JD and Kumar A: Emerging roles of ER stress and unfolded protein response pathways in skeletal muscle health and disease. J Cell Physiol 233: 67-78, 2018.

117. Liu CY, Schröder M and Kaufman RJ: Ligand-independent dimerization activates the stress response kinases IRE1 and PERK in the lumen of the endoplasmic reticulum. J Biol Chem 275: 24881-24885, 2000.

118. Bertolotti A, Zhang Y, Hendershot LM, Harding HP and Ron D Dynamic interaction of BiP and ER stress transducers in the unfolded-protein response. Nat Cell Biol 2: 326-332, 2000.

119. Yoshida H, Matsui T, Yamamoto A, Okada T and Mori K: XBP1 mRNA is induced by ATF6 and spliced by IRE1 in response to ER stress to produce a highly active transcription factor. Cell 107: 881-891, 2001.

120. Shen J, Chen X, Hendershot L and Prywes R: ER stress regulation of ATF6 localization by dissociation of BiP/GRP78 binding and unmasking of Golgi localization signals. Dev Cell 3: 99-111, 2002.

121. Roy A and Kumar A: ER stress and unfolded protein response in cancer cachexia. Cancers (Basel) 11: 1929, 2019.

122. Wu J and Kaufman RJ: From acute ER stress to physiological roles of the Unfolded Protein Response. Cell Death Differ 13: 374-384, 2006.

123. Isaac ST, Tan TC and Polly P: Endoplasmic reticulum stress, calcium dysregulation and altered protein translation: Intersection of processes that contribute to cancer cachexia induced skeletal muscle wasting. Curr Drug Targets 17: 1140-1146, 2016.

124. Barreiro E, Salazar-Degracia A, Sancho-Muñoz A and Gea J: Endoplasmic reticulum stress and unfolded protein response profile in quadriceps of sarcopenic patients with respiratory diseases. J Cell Physiol 234: 11315-11329, 2019.

125. Tam AB, Mercado EL, Hoffmann A and Niwa M: ER stress activates NF- $\mathrm{KB}$ by integrating functions of basal IKK activity, IRE1 and PERK. PLoS One 7: e45078, 2012.

126. White JP, Puppa MJ, Sato S, Gao S, Price RL, Baynes JW, Kostek MC, Matesic LE and Carson JA: IL-6 regulation on skeletal muscle mitochondrial remodeling during cancer cachexia in the ApcMin/+ mouse. Skelet Muscle 2: 14, 2012.

127. Brown JL, Rosa-Caldwell ME, Lee DE, Blackwell TA, Brown LA, Perry RA, Haynie WS, Hardee JP, Carson JA, Wiggs MP, et al: Mitochondrial degeneration precedes the development of muscle atrophy in progression of cancer cachexia in tumour-bearing mice. J Cachexia Sarcopenia Muscle 8: 926-938, 2017

128. VanderVeen BN, Fix DK and Carson JA: Disrupted skeletal muscle mitochondrial dynamics, mitophagy, and biogenesis during cancer cachexia: A role for inflammation. Oxid Med Cell Longev 2017: 3292087, 2017.

129. van der Ende M, Grefte S, Plas R, Meijerink J, Witkamp RF, Keijer $J$ and van Norren $K$ : Mitochondrial dynamics in cancer-induced cachexia. Biochim Biophys Acta Rev Cancer 1870: 137-150, 2018

130. Dave DT and Patel BM: Mitochondrial metabolism in cancer cachexia: Novel drug target. Curr Drug Metab 20: 1141-1153, 2019.

131. Neyroud D, Nosacka RL, Judge AR and Hepple RT: Colon 26 adenocarcinoma (C26)-induced cancer cachexia impairs skeletal muscle mitochondrial function and content. J Muscle Res Cell Motil 40: 59-65, 2019.

132. Pin F, Novinger LJ, Huot JR, Harris RA, Couch ME, O'Connell TM and Bonetto A: PDK4 drives metabolic alterations and muscle atrophy in cancer cachexia. FASEB J 33: $7778-7790,2019$
133. Du Bois P, Pablo Tortola C, Lodka D, Kny M, Schmidt F, Song K, Schmidt S, Bassel-Duby R, Olson EN and Fielitz J: Angiotensin II induces skeletal muscle atrophy by activating TFEB-mediated MuRF1 expression. Circ Res 117: 424-436, 2015.

134. Kadoguchi T, Kinugawa S, Takada S, Fukushima A, Furihata T, Homma T, Masaki Y, Mizushima W, Nishikawa M, Takahashi M, et al: Angiotensin II can directly induce mitochondrial dysfunction, decrease oxidative fibre number and induce atrophy in mouse hindlimb skeletal muscle. Exp Physiol 100: 312-322, 2015

135. Cisternas F, Morales MG, Meneses C, Simon F, Brandan E, Abrigo J, Vazquez Y and Cabello-Verrugio C: Angiotensin-(1-7) decreases skeletal muscle atrophy induced by angiotensin II through a Mas receptor-dependent mechanism. Clin Sci (Lond) 128: 307-319, 2015

136. Yoshida T, Tabony AM, Galvez S, Mitch WE, Higashi Y, Sukhanov S and Delafontaine P: Molecular mechanisms and signaling pathways of angiotensin II-induced muscle wasting: Potential therapeutic targets for cardiac cachexia. Int J Biochem Cell Biol 45: 2322-2332, 2013.

137. Penafuerte CA, Gagnon B, Sirois J, Murphy J, MacDonald N and Tremblay ML: Identification of neutrophil-derived proteases and angiotensin II as biomarkers of cancer cachexia. $\mathrm{Br}$ J Cancer 114: 680-687, 2016

138. Cai X, Zhu C, Xu Y, Jing Y, Yuan Y, Wang L, Wang S, Zhu X, Gao P, Zhang Y, et al: Alpha-ketoglutarate promotes skeletal muscle hypertrophy and protein synthesis through Akt/mTOR signaling pathways. Sci Rep 6: 26802, 2016

139. Liu D, Qiao X, Ge Z, Shang Y, Li Y, Wang W, Chen M, Si S and Chen SZ: IMB0901 inhibits muscle atrophy induced by cancer cachexia through MSTN signaling pathway. Skelet Muscle 9: 8, 2019.

140. Bae T, Jang J, Lee H, Song J, Chae S, Park M, Son CG, Yoon S and Yoon Y: Paeonia lactiflora root extract suppresses cancer cachexia by down-regulating muscular NF- $\mathrm{BB}$ signalling and muscle-specific E3 ubiquitin ligases in cancer-bearing mice. J Ethnopharmacol 246: 112222, 2020.

141. Levolger S, Wiemer EAC, van Vugt JLA, Huisman SA, van Vledder MG, van Damme-van Engel S, Ambagtsheer G, IJzermans JNM and de Bruin RWF: Inhibition of activin-like kinase $4 / 5$ attenuates cancer cachexia associated muscle wasting. Sci Rep 9: 9826, 2019.

142. An JM, Kang EA, Han YM, Oh JY, Lee DY, Choi SH, Kim DH and Hahm KB: Dietary intake of probiotic kimchi ameliorated IL-6-driven cancer cachexia. J Clin Biochem Nutr 65: 109-117, 2019.

143. Liu H, Li L, Zou J, Zhou T, Wang B, Sun H and Yu S: Coix seed oil ameliorates cancer cachexia by counteracting muscle loss and fat lipolysis. BMC Complement Altern Med 19: 267, 2019.

144. Terawaki K, Sawada Y, Kashiwase Y, Hashimoto H, Yoshimura M, Suzuki M, Miyano K, Sudo Y, Shiraishi S, Higami Y, et al: New cancer cachexia rat model generated by implantation of a peritoneal dissemination-derived human stomach cancer cell line. Am J Physiol Endocrinol Metab 306: E373-E387, 2014.

145. Xi QL, Zhang B, Jiang Y, Zhang HS, Meng QY, Chen Y, Han YS, Zhuang QL, Han J, Wang HY, et al: Mitofusin-2 prevents skeletal muscle wasting in cancer cachexia. Oncol Lett 12: 4013-4020, 2016.

146. Toledo M, Busquets S, Penna F, Zhou X, Marmonti E, Betancourt A, Massa D, López-Soriano FJ, Han HQ and Argilés JM: Complete reversal of muscle wasting in experimental cancer cachexia: Additive effects of activin type II receptor inhibition and beta-2 agonist. Int J Cancer 138: 2021-2029, 2016.

147. Khamoui AV, Park BS, Kim DH, Yeh MC, Oh SL, Elam ML, Jo E, Arjmandi BH, Salazar G, Grant SC, et al: Aerobic and resistance training dependent skeletal muscle plasticity in the colon-26 murine model of cancer cachexia. Metabolism 65: 685-698, 2016.

148. Tanaka M, Sugimoto K, Fujimoto T, Xie K, Takahashi T, Akasaka H, Kurinami H, Yasunobe Y, Matsumoto T, Fujino $H$ and Rakugi H: Preventive effects of low-intensity exercise on cancer cachexia-induced muscle atrophy. FASEB J 33: 7852-7862, 2019.

149. Zhang Y, Han X, Ouyang B, Wu Z, Yu H, Wang Y, Liu G and Ji X: Chinese herbal medicine Baoyuan Jiedu decoction inhibited muscle atrophy of cancer cachexia through Atrogin-l and MuRF-1. Evid Based Complement Alternat Med 2017: 6268378, 2017.

150. Sun R, Zhang S, Hu W, Lu X, Lou N, Yang Z, Chen S, Zhang X and Yang $\mathrm{H}$ : Valproic acid attenuates skeletal muscle wasting by inhibiting C/EBPbeta-regulated atrogin1 expression in cancer cachexia. Am J Physiol Cell Physiol 311: C101-C115, 2016. 
151. Zhuang P, Zhang J, Wang Y, Zhang M, Song L, Lu Z, Zhang L, Zhang F, Wang J, Zhang Y, et al: Reversal of muscle atrophy by Zhimu and Huangbai herb pair via activation of IGF-1/Akt and autophagy signal in cancer cachexia. Support Care Cancer 24: 1189-1198, 2016.

152. Chen JM, Yang TT, Cheng TS, Hsiao TF, Chang PM, Leu JY, Wang FS, Hsu SL, Huang CF and Lai JM: Modified Sijunzi decoction can alleviate cisplatin-induced toxicity and prolong the survival time of cachectic mice by recovering muscle atrophy. J Ethnopharmacol 233: 47-55, 2019.

153. Molanouri Shamsi M, Chekachak S, Soudi S, Quinn LS Ranjbar K, Chenari J, Yazdi MH and Mahdavi M: Combined effect of aerobic interval training and selenium nanoparticles on expression of IL-15 and IL-10/TNF- $\alpha$ ratio in skeletal muscle of 4T1 breast cancer mice with cachexia. Cytokine 90: 100-108, 2017.

154. Salazar-Degracia A, Busquets S, Argilés JM, Bargalló-Gispert N, López-Soriano FJ and Barreiro E: Effects of the beta2 agonist formoterol on atrophy signaling, autophagy, and muscle phenotype in respiratory and limb muscles of rats with cancer-induced cachexia. Biochimie 149: 79-91, 2018.

155. Pretto F, Ghilardi C, Moschetta M, Bassi A, Rovida A, Scarlato V, Talamini L, Fiordaliso F, Bisighini C, Damia G, et al: Sunitinib prevents cachexia and prolongs survival of mice bearing renal cancer by restraining STAT3 and MuRF-1 activation in muscle. Oncotarget 6: 3043-3054, 2015.

156. Miao C, Lv Y, Zhang W, Chai X, Feng L, Fang Y, Liu X and Zhang X: Pyrrolidine dithiocarbamate (PDTC) attenuates cancer cachexia by affecting muscle atrophy and fat lipolysis. Front Pharmacol 8: 915, 2017.
157. Kadoguchi T, Takada S, Yokota T, Furihata T, Matsumoto J, Tsuda M, Mizushima W, Fukushima A, Okita K and Kinugawa S: Deletion of $\mathrm{NAD}(\mathrm{P}) \mathrm{H}$ oxidase 2 prevents angiotensin II-induced skeletal muscle atrophy. Biomed Res Int 2018: 3194917, 2018.

158. Bosaeus I: Nutritional support in multimodal therapy for cancer cachexia. Support Care Cancer 16: 447-451, 2008

159. Amano K, Morita T, Miyamoto J, Uno T, Katayama H and Tatara R: Perception of need for nutritional support in advanced cancer patients with cachexia: A survey in palliative care settings. Support Care Cancer 26: 2793-2799, 2018.

160. McClement S: Cancer anorexia-cachexia syndrome: Psychological effect on the patient and family. J Wound Ostomy Continence Nurs 32: 264-268, 2005.

161. Zhang WL, Li N, Shen Q, Fan M, Guo XD, Zhang XW, Zhang Z and Liu X: Establishment of a mouse model of cancer cachexia with spleen deficiency syndrome and the effects of atractylenolide I. Acta Pharmacol Sin 41: 237-248, 2020.

162. Kang HJ, Jeong MK, Park SJ, Jun HJ and Yoo HS: Efficacy and safety of Yukgunja-Tang for treating anorexia in patients with cancer: The protocol for a pilot, randomized, controlled trial. Medicine (Baltimore) 98: e16950, 2019.

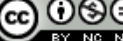

$$
\begin{aligned}
& \text { This work is licensed under a Creative Commons } \\
& \text { Attribution-NonCommercial-NoDerivatives } 4.0 \\
& \text { International (CC BY-NC-ND 4.0) License. }
\end{aligned}
$$

